ISSN: 0213-2060

DOI: http://dx.doi.org/10.14201/shhme201533173199

\title{
CASTROFROILA: LA REPRESENTACIÓN DEL PODER CENTRAL EN LA RIBERA DEL CEA (SIGLOS X-XII) ${ }^{1}$
}

\author{
Castrofroila: the Portrayal of the Central Power in the Cea's Bank \\ $\left(10^{\text {th }}-12^{\text {th }}\right.$ Centuries)
}

\author{
María PÉREZ RODRÍGUEZ \\ Depto. de Historia Medieval, Moderna y Contemporánea. Facultad de Geografía e Historia. Universidad de \\ Salamanca. C/ Cervantes, s/n. E-37002 Salamanca. C. e.: fonsecastell@gmail.com
}

Recibido: 2013-07-25

Revisado: 2014-03-31

Aceptado: 2014-10-03

RESUMEN: Sin descartar la diversidad de funciones tradicionalmente atribuidas a castros y castillos, en los últimos ańos se ha incidido sobre todo en su papel como centros de representación del poder. El ejemplo que aquí presentamos viene caracterizado por la fuerte y continua vinculación que se establece entre Castro Froila-Mayorga, en la ribera del Cea, y la autoridad central. A través de las fuentes documentales y arqueológicas sabemos de la existencia de este enclave y de la importante función política que desde él se ejerció, intensificada tras la división del reino a la muerte de Alfonso VII y el recrudecimiento del conflicto entre León y Castilla.

Palabras clave: Castillo; Centros de representación; Poder central; Poderes señoriales; Tenencias; Villas reales.

ABSTRACT: It is known that researchers, during last years, have focused on the role of castra and castles as subjects of power representation beyond their functions that traditionally

1 Este trabajo se ha realizado al amparo de una Beca de Formación del Personal Investigador concedida por la Junta de Castilla y León (Orden EDU/1867/2009, de 21 de septiembre, apartado G) en colaboración con el Fondo Social Europeo. 
MARÍA PÉREZ RODRÍGUEZ

CASTROFROILA: LA REPRESENTACIÓN DEL PODER CENTRAL EN LA RIBERA DEL CEA

(SIGLOS X-XII)

have been given to them. The main attribute of the example we are going to display is its strong and continuous linkage between Castro Froila-Mayorga, a village in the River Cea shore, and Central Authority. We know the existence of this location through the documentary and archeological sources. Documents and material evidences show us the important political function which Castro Froila historically played, much more after the death of king Alfonso VII and his partition of the kingdom of Leon and Castile between his sons, a fact which did more lively the conflict between both kingdoms.

Keywords: Castle; Representation Centres; Central Power; Seigneurial Power; Tenancies; Royal Villages.

SUMARIO: 0 Introducción. 1 Castrofroila en los siglos x y xI. 2 La tenencia de Castro Froila, ¿̨un caso particular? 3 De Castro Froila a Mayorga: el nacimiento de la villa regia. 4 Referencias bibliográficas.

\section{INTRODUCCIÓN}

Castros y castillos se han convertido en los últimos años en uno de los temas que más poderosamente ha captado la atención de los medievalistas. Su estudio ha sido abordado desde múltiples ópticas en un intento de comprender la amplia red de funciones asumidas por estas estructuras emblemáticas, convertidas en verdaderos hitos del paisaje medieval. En este proceso de análisis, el papel militar y geoestratégico originalmente atribuido a la fortificación se ha visto complementado por otro tipo de atribuciones, una de cuyas consecuencias ha sido la proliferación del número de monografías y estudios en relación a esta compleja temática de la que, a pesar de los constantes avances, aún queda mucho por investigar. Para la franja noroeste peninsular contamos con un interesante elenco de obras destinadas al análisis de estos enclaves, cuyo número se ha visto además incrementado recientemente a través de las intervenciones arqueológicas emprendidas en este cuadrante geográfico ${ }^{2}$.

Junto a ellas, se hace necesario tomar en consideración obras ya clásicas como la de Gutiérrez González ${ }^{3}$, un interesante referente a la hora de abarcar el estudio del papel

2 Sirvan como ejemplos los estudios recopilados en la obra: Quirós CASTILlo, José Antonio y TeJADo Sebastián, José María. Los castillos altomedievales en el noroeste de la Peninsula Ibérica. Documentos de arqueología medieval 4. Bilbao: Universidad del País Vasco, 2012.

3 Gutiérrez GonzÁlez, José Avelino. Fortificaciones y feudalismo en el origen y formación del Reino leonés (siglos IX-XIII). Valladolid: Secretariado de Publicaciones, 1995. La labor de investigación desplegada por este autor en relación a los centros fortificados es realmente amplia. Junto a la obra citada destacan «Expansión y consolidación feudal del Reino de Asturias: las fortificaciones de Alfonso III en la montaña leonesa». En Homenaje a Juan Uria Riu. Oviedo: Universidad de Oviedo, 1997, vol I, pp. 275-300; «Excavaciones arqueológicas en el castillo de Curil (Peñaferruz, Gijón): campañas 1999-2002». En Excavaciones arqueológicas en Asturias: 1999-2002. Oviedo: Gobierno del Principado de Asturias, 2007, pp. 163-176; «Castillos y sistemas de defensa en los reinos de León y Castilla». En Iglesia Duarte, José Ignacio de la (coord.). II Semana de Estudios Medievales. Nájera del 5 al 9 de agosto de 1991. Logroño: Instituto de Estudios Riojanos, 1992, pp. 31-48. Gutiérrez González, José Avelino y SuÁrez Manjón, Patricia. "Castillos y fortalezas feudales en Asturias: metodología para su estudio». Territorio, Sociedad y Poder. Revista de Estudios Medievales, 2007, vol. 2, pp. 5-36. 
MARÍA PÉREZ RODRÍGUEZ

CASTROFROILA: LA REPRESENTACIÓN DEL PODER CENTRAL EN LA RIBERA DEL CEA

(SIGLOS X-XII)

desempeñado por estos centros en la gestación y desarrollo del feudalismo y en relación al control territorial y socio-económico. Resultaría extremadamente complejo realizar siquiera una breve recopilación dado el elevadísimo número de estudios encargados de abordar semejantes cuestiones ${ }^{4}$. Este complejo panorama que se perfila en relación a la temática que aquí presentamos ha de entenderse dentro de un contexto concreto, que no es otro que la evolución y desarrollo alcanzados por el propio debate historiográfico y por la renovación observada por el método arqueológico, generalizada a buena parte del continente europeo. Como en la Península Ibérica, las investigaciones llevadas a cabo en países como Italia ${ }^{5}$ los resultados de las mismas se presentan como una clara muestra del interés suscitado tanto a nivel arqueológico como documental por estos enclaves necesariamente asociados a la presencia de ciertas formas de poder y al ejercicio del mismo. Precisamente ha sido esta relación la responsable de articular el debate entablado entre los medievalistas, haciendo factible la gestación de algunos modelos interpretativos entre los que se hace necesario destacar el incastellamento propuesto por Toubert hace ya varias décadas y cuya revisión a lo largo de estos años ha derivado en el enriquecimiento semántico del término. En cualquier caso, captar y analizar la naturaleza del vínculo creado entre poderes y centros de representación resulta una tarea compleja pero esencial de cara a comprender algunos de los patrones sobre los que se asentó el proceso de feudalización y señorialización de una sociedad como la medieval.

Teniendo en cuenta tales premisas, el ejemplo que aquí analizamos constituye una clara manifestación del vínculo gestado entre el centro jerárquico y el poder que en él aparece representado y que en este caso concreto se materializa en la figura del propio monarca. De la naturaleza de esta relación tenemos constancia documental, siendo estas mismas fuentes escritas las que permiten adivinar algunas de las principales funciones asimiladas por un castillo cuya existencia viene avalada, además, por la arqueología. Este hecho no deja de ser representativo en la medida en que ha posibilitado el desarrollo y puesta en práctica de una metodología que, si bien observa un predominio de la lectura

4 Sin ánimo de exhaustividad, algo que por otro lado resultaría imposible de llevar a cabo en un estudio de estas características, destacamos algunas de las obras vinculadas al análisis de las fortificaciones: VÁzquez Álvarez, Roberto. "Hábitat fortificado y feudalismo en el reino de Castilla entre los siglos viII al XiII». En Quirós Castillo y Tejado Sebastián (eds.), Los castillos altomedievales, pp. 291-308; "Castros, castillo y torres en la organización social del espacio en Castilla: el espacio del Arlanza al Duero (siglos IX a XIII)». En García de Cortázar, José Ángel (coord.). Del Cantábrico al Duero: trece estudios sobre organización social del espacio en los siglos VIII a XIII. Santander: Universidad de Cantabria-Parlamento de Cantabria, 1999, pp. 351-374; Batet i Company, Carolina. «La marca encastellada? Castells i pautas d'assentament a la Marca del Comtat de Barcelona (segles X-XI)». Afers, 1995, vol. 10, n. ${ }^{\circ}$ 21, pp. 341-360.

5 El número de estudios efectuados en Italia y los resultados derivados de las intervenciones arqueológicas llevadas a cabo son muy amplios y se encuentran estrechamente vinculados al modelo de incastellamento ya citado. Como ejemplos: Toubert, Pierre. Castillos, señores y campesinos en la Italia medieval. Barcelona: Crítica, 1990; Nuccioti, Michele y Leporatti, Silvia. «Organizzazione del cantiere di una fortaleza rurale di XIII secolo: il caso di Montelaterone (Monte Amiata - Toscana)». Arqueología de la Arquitectura, 2003, vol. 2, pp. 255-265; Varaldo, Carlo. "Incastellamento e popolamento nel Savonese». En Benente, Fabrizio (a cura di). L'incastellamento in Liguria. X-XII secolo. Bilancio e distini di un tema storigrafico. Bordighera: Istituto Internazionale di Studi Liguri, 2000, pp. 131-161; Wiскнам, Chris. "A che sirve l'incastellamento?». En Barceló, Miquel y Toubert, Pierre (dirs.). L'incastellamento. Actas de las reuniones de Girona y de Roma. Roma: École Française de Rome, 1998, pp. 31-42. 


\section{MARÍA PÉREZ RODRÍGUEZ \\ 176 \\ CASTROFROILA: LA REPRESENTACIÓN DEL PODER CENTRAL EN LA RIBERA DEL CEA}

y análisis documental, se sirve asimismo de la información que desde el punto de vista material nos proporcionan tanto el inventario arqueológico de la provincia de Valladolid como los distintos estudios monográficos que abordan estos planteamientos. Una vez establecidos, cabe seńalar que la finalidad que se pretende alcanzar con estas páginas no es otra que contribuir al conocimiento del feudalismo a través de uno de los aspectos claves en su definición: la identificación y análisis, a través del castillo, de las pautas que regularon ciertas fórmulas de representación del poder en la Ribera del Cea y la naturaleza de los vínculos gestados entre los distintos grupos que sustentaban dicho poder.

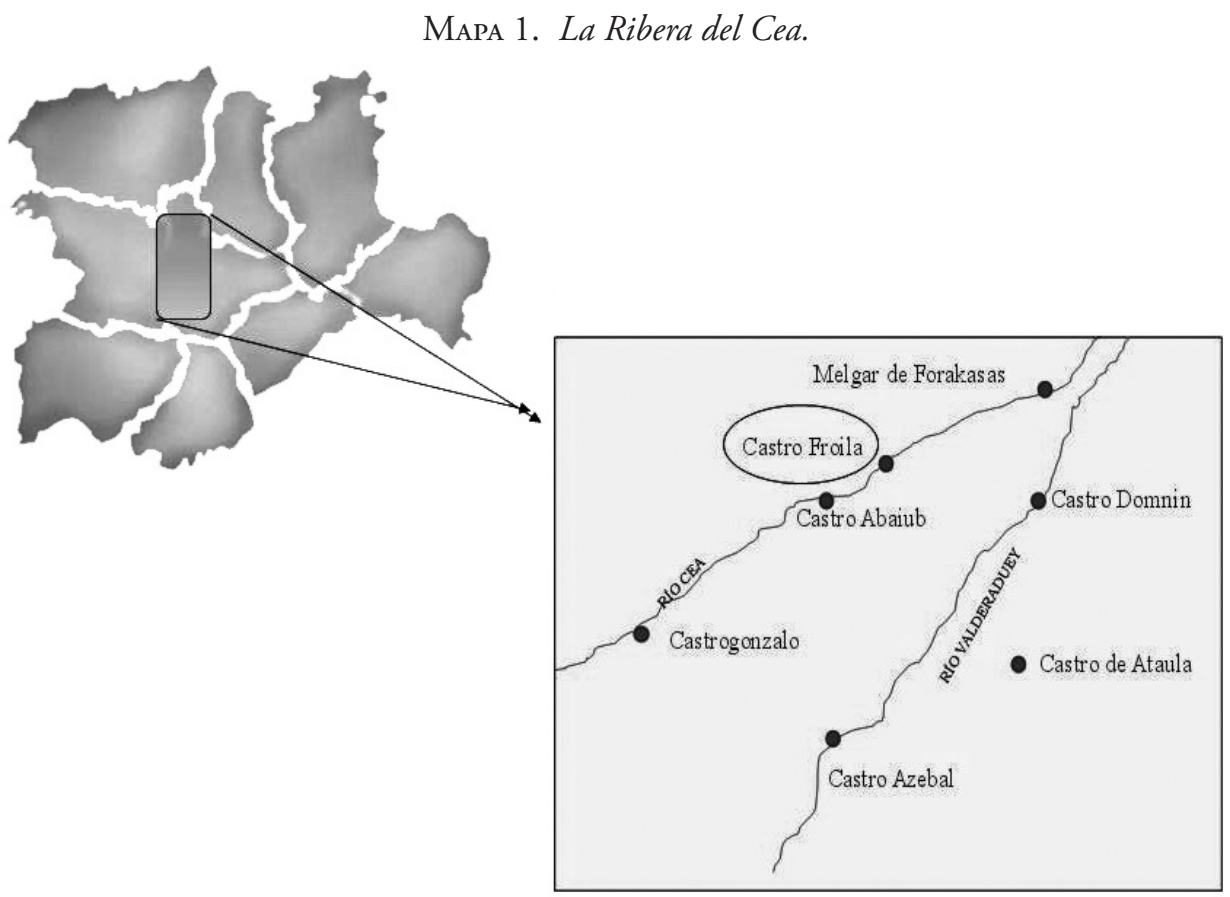

Fuente: http://www.castillayleonjoven.com/imagenes/estructura/mapa/mapa.jpg [consultado: 03-07-2013].

Para ello hemos tomado como núcleo especialmente representativo de las cuestiones que aquí se pretenden analizar el lugar de Castro Froila. Localizado en la Tierra de Campos vallisoletana, limitando al oeste con el páramo leonés y con una altitud que ronda los 780 metros $^{6}$, se recorta sobre una superficie llana, con clara tendencia a la horizontalidad tal y como corresponde a los terrenos de campińa. Junto a núcleos como Castro Mazaref, Castro Abaiub, Melgar de Abduzi y Melgar de Forakasas, formaba parte de la red de asentamientos que se perfilaba en una zona cuyas características geomorfológicas convertían

6 Dato tomado del Inventario Arqueológico de la Provincia de Valladolid. Municipio de Mayorga. 
MARÍA PÉREZ RODRÍGUEZ

CASTROFROILA: LA REPRESENTACIÓN DEL PODER CENTRAL EN LA RIBERA DEL CEA

(SIGLOS X-XII)

a estos suelos en un escenario especialmente apto para la explotación y aprovechamiento agrícolas, condiciones que los distintos grupos humanos que poblaron este espacio supieron aprovechar. A la luz de tales consideraciones no ha de extrañar que la mayoría de los núcleos altomedievales que se documentan en la región, y de los cuales Castro Froila no es una excepción, se emplace sobre los restos de épocas anteriores, como han permitido constatar las intervenciones arqueológicas llevadas a cabo ${ }^{7}$.

\section{Castrofroila en los siglos X y XI}

Sabemos a través de los textos que en el año 1181 Mayorga recibía carta foral de manos del rey Fernando II, encargado de autorizar la repoblación del lugar ${ }^{8}$, convirtiéndose así en una de las múltiples villas regias que en ese momento están floreciendo al norte del Duero' . No obstante, mucho antes de que este acontecimiento tuviese lugar, en el año 891, las fuentes escritas hacían referencia al valle de Castro Froila ${ }^{10}$, dando así a entender que la articulación de este espacio se hacía efectiva desde un enclave que actuaba como centro jerárquico, siguiendo una lógica que se constata de forma similar para otros sectores geográficos y que garantizaba la progresiva incorporación de estos territorios al programa político desplegado por la autoridad central ${ }^{11}$. Sin embargo, las dudas en relación a la autenticidad de este texto nos obligan a ser cautelosos incluso en lo que a este aspecto se refiere. Va a ser en el año 1074 cuando, a raíz de la donación emprendida por María Gutiérrez y sus hermanas a favor de Velasco Vélaz, su mujer e hijos, encontremos, sin sesgo de duda, la mención al territorio Castro Froila ${ }^{12}$. En cualquier caso, en este contexto de

\footnotetext{
Téngase en cuenta que se están tomando en consideración los restos documentados en el llamado Teso Miravete, donde Gutiérrez González sitúa el antiguo Castro Froila, hipótesis que se discutirá en páginas sucesivas. La adscripción de este emplazamiento a la I Edad de Hierro se fundamenta en el hallazgo de algunos restos cerámicos definidos por bordes remarcados por baquetones al exterior y un galbo decorado con líneas incisas. Vid. Inventario Arqueológico de la Provincia de Valladolid. Municipio de Mayorga.

8 Rodríguez Fernández, Justiniano. "Apuntes para la historia de Mayorga». Archivos Leoneses, 1968, vol. 44, p. 318.

9 González DíEz, Emiliano. El régimen foral vallisoletano. Una perspectiva de análisis organizativo del territorio. Valladolid: Excma. Diputación Provincial de Valladolid, 1986, pp. 49-51 y 112-117.

10 Se trata en este caso de la fundación y dotación protagonizada por Alfonso III y su esposa Jimena del monasterio de San Adriano de Tuñón. Dicha dotación implicaba la entrega de ciertos bienes, entre los que destaca in valle Castro Froila villa Bovatella cum ecclesia Sanctis Feliciis iusta fluvium. García Larragueta, Santos A. Colección de documentos de la catedral de Oviedo. Oviedo: [s. n.], 1962, doc. 13. No obstante, existen serias dudas sobre el carácter de este documento. Mientras que Gutiérrez González parece servirse de la obra de García Larragueta como punto de referencia y Sánchez-Albornoz lo considera auténtico en su totalidad, Floriano expone y justifica sus dudas sobre el mismo. Sobre tales cuestiones remitimos al estudio realizado por FLORIANO, Antonio C. Diplomática española del periodo astur. Estudio de las fuentes documentales del Reino de Asturias (718910). Vol. II. Oviedo: Diputación Provincial de Oviedo. Instituto de Estudios Asturianos, 1951, pp. 187-192.

11 En su estudio sobre las fortificaciones leonesas, Gutiérrez González constata un planteamiento similar, basado en la existencia de entidades territoriales que reciben la misma designación que aquellos centros desde los que se ejerce su control. Así sucedería por ejemplo con los territorios de Alba o Gordón. Vid. Gutiérrez GonzÁlez, Fortificaciones y feudalismo, p. 113.

12 Herrero de la Fuente, Marta. Colección diplomática del monasterio de Sahagún, Vol. II. León: Centro de Estudios e Investigación San Isidoro, 1988, doc. 733. (A partir de ahora CDMS-II, III).
} 
MARÍA PÉREZ RODRÍGUEZ

paulatina expansión hacia el sur no podemos pasar por alto la relevancia que encierra la denominación del lugar, altamente significativa por encontrarse fundamentada en la utilización de una fórmula que se reitera de forma similar en centros muy próximos. Se trata del empleo del término "castro» al que se suma un antropónimo, aspecto que ha sido bien estudiado por autores como Carrera de la $\operatorname{Red}^{13} \mathrm{o}$ Martínez Sopena ${ }^{14}$. En efecto, podemos comprobar que esta formulación se repite a lo largo de las riberas del Cea y del Valderaduey como se desprende de los cuantiosos topónimos que asumen estas características; tal sería el caso de los muy próximos Castro Abaiub, Melgar de Foracasas, Castro Abduci o Castro Mazaref por citar solo algunos ejemplos ${ }^{15}$. Semejante hecho ha sido interpretado como el resultado del programa político y la actividad repobladora emprendida por la monarquía asturleonesa en su descenso hacia la línea del Duero ${ }^{16}$. Así, del mismo modo que Iben Tajón para el caso de Foracasas ${ }^{17}$, la figura de Froila podría estar haciendo referencia a uno de los grandes propietarios que a comienzos del siglo $\mathrm{x}$, si no antes, se encontraban instalados en la zona con un rico patrimonio y muy posiblemente vinculados a la corte regia o a la propia figura del monarca. Sobre estas figuras recaería la responsabilidad de articular y controlar estos territorios, labor que se haría efectiva desde estos centros que, de un modo u otro, quedan vinculados a estos personajes. No conocemos con certeza el origen de estos personajes y no podemos más que aventurar su rango de gentes que, en cierta medida, destacarían o sobresaldrían a nivel local. De lo que no cabe duda es de que, de alguna manera, su huella quedó plasmada en estos enclaves que acabaron por asumir el antropónimo de quien ejerció el control y dominio desde ellos.

Poco más es lo que se puede señalar en relación al Castro Froila del siglo $\mathrm{x}$ dado el carácter y la limitación cuantitativa de los documentos para las primeras etapas de vida de este centro. Gutiérrez González, en contraposición a la opinión de Mínguez Fernández ${ }^{18}$,

13 Buena parte de los topónimos presentes en este sector evidencian un origen árabo-bereber, si bien en este caso se trata de un nombre de asignación germánica, derivado de Fraujis y que podemos traducir como «señor». Carrera de la Red, Fátima. Toponimia de los valles del Cea, Valderaduey y Sequillo. León: Institución Fray Bernardino de Sahagún de la Excma. Diputación Provincial, 1988, p. 619.

14 Martínez Sopena, Pascual. La Tierra de Campos occidental. Poblamiento, poder y comunidad en los siglos X a XIII. Valladolid: Institución Cultural Simancas, 1985.

15 Para un estudio más detallado de estos aspectos remitimos a la obra de Martínez Sopena, La Tierra de Campos occidental, pp. 91-100.

16 Sobre este particular puede resultar de interés el estudio realizado por Mínguez Fernández, José María. «Poderes locales en el espacio central leonés durante el periodo astur». En Fernández Conde, Francisco Javier y García de Castro Valdés, César (eds.). Territorio, Sociedad y Poder. Revista de Estudios medievales. Symposium Internacional Poder y Simbología en Europa, siglos VIII-X. Actas del Symposium Internacional convocado en Oviedo, 22-27 de septiembre del 2008. Oviedo: Ediciones Universidad de Oviedo, 2009, Anejo n.o 2, pp. $199-214$.

17 A pesar de que son diversos los autores que han aceptado esta propuesta en relación a la figura de Forakasas, existe una gran controversia sobre el origen de este personaje. Como ejemplo de esta variedad de opiniones remitimos a los datos aportados por Martínez Sopena, La Tierra de Campos occidental, p. 98 y SÁNCHez Badiola, Juan José. La configuración de un sistema de poblamiento y organización del espacio: el territorio de León (siglos IX-XI). León: Universidad de León, 2002, p. 111.

18 Para este autor no existen indicios que permitan atribuirle a este centro la función de sede política en un momento tan temprano. Mínguez Fernández, José María. «Pervivencia y transformaciones de la concepción y práctica del poder en el reino de León (siglos X-XI)». Studia Historica. Historia Medieval, 2007, vol. 25 , pp. 56-57. 
MARÍA PÉREZ RODRÍGUEZ

CASTROFROILA: LA REPRESENTACIÓN DEL PODER CENTRAL EN LA RIBERA DEL CEA

(SIGLOS X-XII)

Fото 1. Vista aérea del actual núcleo de Mayorga y el Teso Miravete a orillas del Cea.

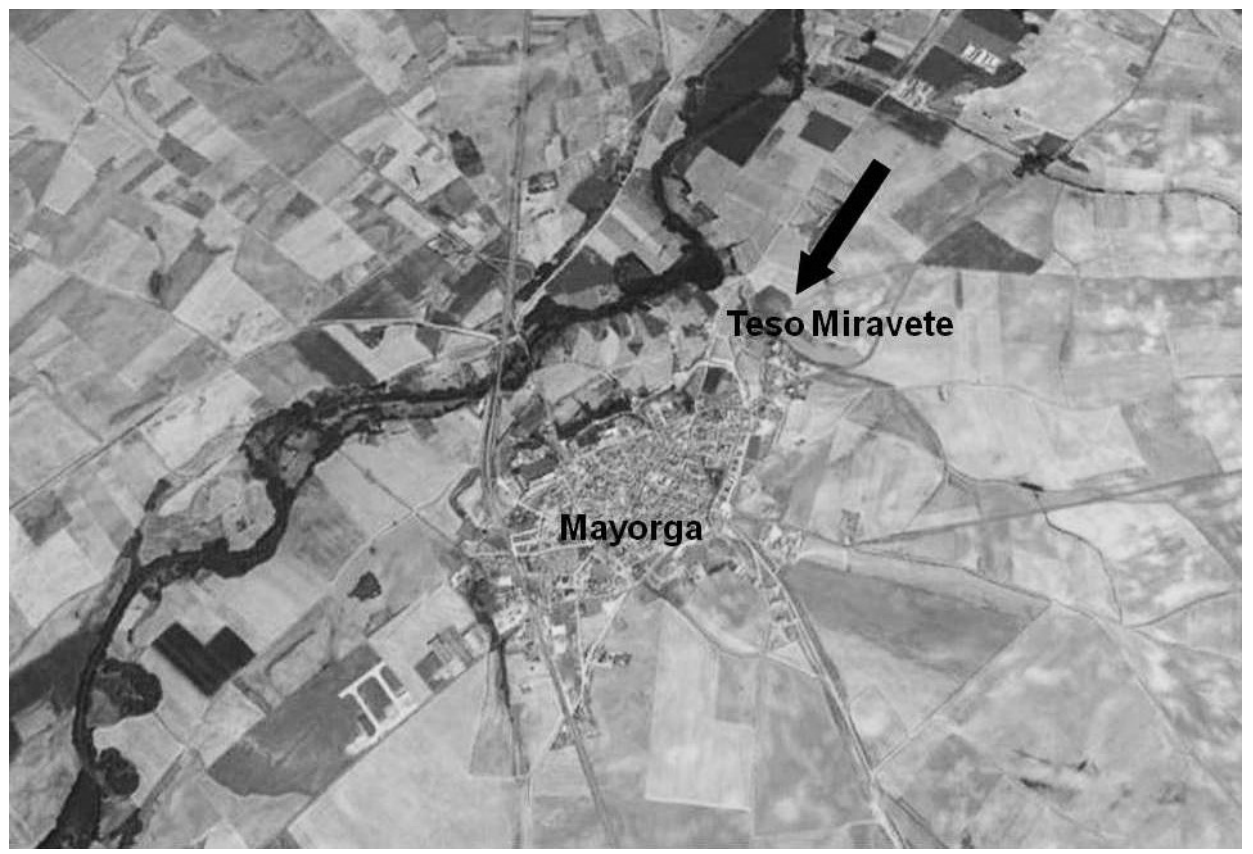

Fuente: https://maps.google.es/maps?q=mayorga \&um=1\&ie=UTF-8\&hl=es\&sa=N\&tab=wl [consultado: 03-07-2013].

le atribuye ya en este momento funciones de índole política y jurisdiccional, constatando la presencia de un lugar fortificado, centro jerárquico de control y dominio territorial cuyo emplazamiento geográfico no parece estar, sin embargo, demasiado claro ${ }^{19}$. En este sentido, no existe consenso entre los distintos autores sobre la posible ubicación original de Castro Froila, aunque el mismo Gutiérrez González localiza este centro en uno de los cerretes próximos al actual Mayorga, en el Teso Miravete ${ }^{20}$. En la parte superior del mismo se han podido identificar restos materiales de construcción, tales como tejas curvas, ladrillos y piedras areniscas, asignables a una fortificación, y algunas piezas cerámicas -muy escasasrepresentadas por fábricas de cocción reductora y reductora-oxidante con decoración a base

19 Gutiérrez González, Fortificaciones y feudalismo, p. 337.

20 Frente a la hipótesis defendida por Gutiérrez González, quien, además de ubicar Castro Froila en el Teso de Miravete, lo pone en relación con el Castro Iudeorum de Maiorica (Gutiérrez González, Fortificaciones y feudalismo, pp. 337-338). Rodríguez Fernández ubica el Castro Iudeorum en el lugar conocido como Las Motas, también en las proximidades del actual centro urbano de Mayorga y separado del núcleo urbano por una suave vaguada donde según el autor parecen constatarse restos de una fortificación medieval a través de la presencia de los restos de muros en la vertiente norte del cerro. Rodríguez Fernández, "Apuntes para la historia", pp. 346-347. Para Carrera de la Red el castro se ubicaría en Sahelices o en sus proximidades, posiblemente en alguno de los tesos que dominan la vega. Carrera de la Red, Toponimia de los valles, p. 138. 
MARÍA PÉREZ RODRÍGUEZ

CASTROFROILA: LA REPRESENTACIÓN DEL PODER CENTRAL EN LA RIBERA DEL CEA

(SIGLOS X-XII)

de incisiones a peine formando bandas horizontales y verticales, atribuibles al horizonte cultural medieval ${ }^{21}$.

En cualquier caso, y a pesar de contar con menciones tempranas sobre Castro Froila, es a lo largo de la centuria siguiente cuando el número de alusiones aumenta considerablemente; y es precisamente a partir del siglo XI cuando encontramos las alusiones más interesantes a este núcleo que, como tendremos ocasión de analizar más adelante, parece haber ido asumiendo una diversidad de funciones de las que nos ha quedado constancia documental. Pero semejantes hechos han de ponerse en relación directa con el fenómeno de feudalización y señorialización que estaba experimentando la sociedad medieval y que ya en el siglo xi parece mostrarse bien consolidado. En el caso que aquí nos ocupa, dicho fenómeno ha sido analizado en profundidad por Martínez Sopena a través de la identificación de los principales grupos magnaticios y de la acción de expansión patrimonial emprendida por estos en ese sector ${ }^{22}$. Esta tendencia al desarrollo de políticas expansivas protagonizadas por las elites señoriales, tanto laicas como eclesiásticas, y las disputas protagonizadas con el fin de hacerse con el mayor número posible de derechos sobre las comunidades rurales, se convirtió en una constante y en la base de la propia señorialización de la sociedad medieval. La presencia en Tierra de Campos de parentelas como las de los Flaínez, los Banu Mirel o los Alfonso ${ }^{23}$, entre otros, avalan estas afirmaciones. Se trata de importantes familias aristocráticas que desde el siglo $\mathrm{x}, \mathrm{y}$ junto a las instituciones monásticas, habían ido adquiriendo ciertas propiedades y derechos en la zona, hecho sobre el que vendría a fundamentarse a su vez la progresiva disolución de las antiguas formas de ordenación comunitaria. Los propios documentos vienen a referir el modo mediante el cual estos entes señoriales se van haciendo progresivamente con el control sobre ciertos lugares e infraestructuras, estas últimas posiblemente de uso comunal. Así sucedería, por ejemplo, con el acueducto que en el año 939 Fernando y su familia venden al monasterio de Sahelices ${ }^{24}$, o la venta que en el año 951 protagoniza un tal Dolquiti a favor de Sahagún ${ }^{25}$, si bien el caso más

21 Datos extraídos del Inventario Arqueológico de la Provincia de Valladolid. Municipio de Mayorga.

22 El número de estudios realizados por el autor en relación a estas cuestiones es muy amplio. A modo de ejemplo ténganse en cuenta: Martínez Sopena, La Tierra de Campos occidental, en especial la sección segunda, dedicada al estudio de los grandes propietarios; "Parentesco y poder en León durante el siglo XI. La “casata” de Alfonso Díaz". Studia Historica. Historia Medieval, 1987, vol. 5, pp. 33-88; "El conde Rodrigo de León y los suyos: herencia y expectativa del poder entre los siglos x y XII». En PAsTor DE TognerI, Reyna (ed.). Relaciones de poder, de producción y de parentesco en la Edad Media y Moderna: aproximación a su estudio. Madrid: Consejo Superior de Investigaciones Científicas, 1999, pp. 51-84.

23 Remitimos una vez más al análisis efectuado por Martínez Sopena, La Tierra de Campos occidental, pp. 327-467. Aunque mucho más genérica, también resulta de utilidad la obra de Torres Sevilla, Margarita. Linajes nobiliarios de León y Castilla (siglos IX-XIII). Valladolid: Junta de Castilla y León, Consejería de Educación, 1999.

24 Ego Fernando et uxor mea Elbegoto, et filio nostro Iohanne. Placuit nobis atque convenit nullius cogentis imperio nec suadentis fratres de Sancto Felice aqua cum suo aqueducto in rivo Ceia ex ereditate patrum nostrorum et de eredibus nostris. Mínguez Fernández, José María. Colección diplomática del monasterio de Sahagún (siglos $I X$ $y X$ ). León: Centro de Estudios e Investigación San Isidoro, 1976, doc. 73. (A partir de ahora CDMS-ss. IX-X).

25 Rodríguez Fernández, Justiniano. Reyes de León. Ordoño III. León: Ediciones Leonesas, 1982, Documentación serie B, cartas particulares, p. 316, doc. 6. 
MARÍA PÉREZ RODRÍGUEZ

CASTROFROILA: LA REPRESENTACIÓN DEL PODER CENTRAL EN LA RIBERA DEL CEA

(SIGLOS X-XII)

representativo lo constituye la donación de un prado que en el año 932 llevó a cabo la collatio de Melgar a favor del monasterio de San Juan ${ }^{26}$.

Esta expansión señorial proseguirá a lo largo del siglo XI favorecida, además, por las políticas matrimoniales emprendidas por la mayor parte de estas familias. De hecho, por mencionar algún ejemplo representativo de los abundantes casos documentados, se sabe que Osorio Osóriz, hijo de Osorio Ermé́ldez y, por tanto, miembro directo de los Banu Mirel, casó con Munia Muñiz, de la «casata» de los Alfonso ${ }^{27}$. El matrimonio, junto con sus hijos Gutierre, Marina, Elvira y Adosinda, donará en el año 1064 la mitad del monasterio de San Felices a favor de Sahagún ${ }^{28}$. Este mismo ejemplo nos va a servir además para entender la diversidad de formas que a lo largo de la Alta Edad Media asumió el poder o, dicho de otro modo, la variedad de fórmulas bajo las cuales este se vio representado. Dicho cenobio de San Felices -futuro Sahelices de Mayorga- se habría quedado bajo el control de los Banu Mirel a través precisamente del establecimiento de estos lazos de parentesco, en la medida en que fue una tal Adosinda, esposa de Ermeildo Núñez, quien lo aportó a la familia por medio de su matrimonio. Pero el dato más interesante que aquí nos importa destacar es que originalmente el monasterio parece haber formado parte del patrimonio regio, siendo cedido por Ramiro III al obispo de León, Velasco, quien lo habría traspasado a su presunta hija, Adosinda ${ }^{29}$. En este sentido cabría destacar cómo, más allá de la importancia que el monasterio pudiese haber tenido para esta familia, su cesión habría entrado a formar parte del juego político desplegado por el poder central en su pretensión de establecer ciertos vínculos de poder con importantes miembros de la aristocracia y contar así con su apoyo; qué mejor forma de hacerlo que granjeándose el respaldo del obispo leonés.

Por otro lado, y entre las cuestiones que aquí estamos planteando, es importante no perder de vista que este cenobio de San Felices habría actuado, hasta el momento de su donación, como un importante mecanismo mediante el cual la monarquía se habría hecho visible en una zona donde el número de propiedades y bienes regios no era precisamente abundante, máxime si se compara con la situación observada en sectores geográficos no tan alejados como podría ser, por citar algún ejemplo concreto, el valle de Vidriales. En este caso, además de la mención documental explícita a bienes de realengo, el número de donaciones, protagonizadas por la monarquía a favor de señores laicos y eclesiásticos, y su naturaleza permiten percibir claramente la diferencia entre ambas zonas ${ }^{30}$.

26 Ego Filauria, Teoda, Adica, Gundisalvo, Taione, Isciame, Gomiz, item Adica, Valdeo et omni collacio de Melgare una cum domno Rexindo damus in sancta basilica Sancti Iohannis et ad abbade Iubla uno prato ad Fonte Auria quam circa ribulo de Midonia pro animas nostras et de parentes nostros. CDMS-ss. IX-X, doc. 44.

27 Martínez Sopena, «Parentesco y poder en León durante el siglo XI», p. 76.

28 Osoro Osoriz, una cum coniuge mea Monnia et filiis meis Gutierre, Marina, Gelvira et Adosinda... offerimus adque concedimus... monasterium de Sancti Felicis, quod dicitur Bobatella. CDMS-II, doc. 640.

29. Martínez Sopena, La Tierra de Campos Occidental, p. 348.

30 Este planteamiento no debe entenderse bajo la óptica de una ausencia total de bienes en manos del poder regio, si bien es cierto que la comparación con otras zonas donde el patrimonio del rey parece mostrarse más elevado permite concluir un alto grado de heterogeneidad en la definición de los mecanismos de poder y representación. Así, por ejemplo, en el año 1158 el rey Fernando II le concederá al prior Domingo un excusado en Mayorga (García Lobo, Vicente. Colección documental del monasterio de San Miguel de Escalada (940-1605). León: Centro de Estudios e Investigación San Isidoro, 2000, doc. 4); en 1168 el mismo monarca 
En cualquier caso, la utilización por parte de la monarquía del monasterio de San Felices como vehículo de representación y esta escasa presencia de bienes regios en la Ribera del Cea deben ponerse en relación con aspectos no menos importantes que parecen encontrar su razón de ser en el propio acto repoblador. Esta propuesta ha sido defendida por autores como Martín Viso, quien, tras analizar la situación observada en el sector berciano, concluye que la carencia de patrimonio regio en la zona respondería a la falta de una implantación directa en la zona por parte del poder central ${ }^{31}$. En el caso que nos ocupa, como hemos tenido ocasión de comprobar, esta actividad repobladora recayó sobre una serie de poderes locales encargados de organizar la ordenación del poblamiento y de los recursos humanos y naturales insertos en su campo de actuación, hecho que vendría a explicar la relativa escasez patrimonial regia y la utilización de la red monástica como mecanismo intermediario.

A la luz de tales datos, que no pretenden sino contextualizar el tema que aquí desarrollamos, cabría preguntarse qué es lo que sucede con el enclave de Castro Froila desde mediados del siglo x hasta aproximadamente la mitad del xI. Lo cierto es que carecemos de datos al respecto y no contamos con información documental que nos permita emitir una respuesta precisa. Que el enclave existió y mantuvo su vigencia durante esta etapa parece avalarse a través de los datos arqueológicos, si bien lo que no podemos defender en este momento es su vínculo directo con la monarquía. Sí hay que tener en cuenta que la situación geográfica de este núcleo fue clave tanto en el transcurso de la implantación y asentamiento de este monarca en el trono castellano, y más tarde leonés, como posteriormente, cuando los reinos de Castilla y León se dividen tras la muerte de Alfonso VII. Tampoco se puede perder de vista que la Ribera del Cea formó parte de una franja espacial intensamente seńorializada donde se hizo efectiva la conjunción de poderes muy diversos que pugnaban por consolidar su control y dominio sobre la zona. Es posible que la suma de todos estos factores, a los que debemos ańadir los ya mencionados, condicionase tanto la naturaleza del territorio, altamente fragmentado, como la forma en la que estos poderes pudieron haber ejercido el control sobre el mismo.

En cualquier caso, la situación soportó ciertas transformaciones con el advenimiento de la dinastía navarra, hecho que también supondrá una modificación importante en la

otorga al monasterio de Eslonza un huerto en Mayorga (GonzÁlez González, Julio. Regesta de Fernando II. Madrid: Consejo Superior de Investigaciones Científicas, Instituto Jerónimo Zurita, 1943, doc. 16). Por el contrario, en el año 1033 la infanta Elvira, hija de Vermudo II, entrega a favor del monasterio de Santa Marta de Tera la villa de Pozuelo de Vidriales (Cavero Domínguez, Gregoria y Martín López, Encarnación. Colección documental de la Catedral de Astorga. Vols. I y II. León: Centro de Estudios e Investigación San Isidoro, 1999, doc. 271 (a partir de ahora CDCA-I, II); en 1103 Alfonso VI confirma las donaciones realizadas al monasterio de San Pelayo y San Isidoro de León por sus predecesores, entre las que se incluía, por ejemplo, la mitad de la villa de Rosinos de Vidriales (Gambra, Andrés. Alfonso VI. Cancillería, curia e imperio. León: Centro de Estudios e Investigación San Isidoro, 1997-1998, doc. 175).

31 MarTín Viso, Ińaki. «La monarquía asturleonesa en el Bierzo (siglos IX-x)». En Arízaga BolumBURU, Beatriz et ál. (eds.). Mundos medievales: espacios, sociedades y poder. Homenaje al profesor José Ángel García de Cortázar y Ruiz de Aguirre. Santander: PUbliCan, 2012, vol. I, pp. 733-746; Carvajal Castro, Álvaro y MARTín VIso, Ińaki. «Historias regionales de la repoblación: los reyes asturleoneses y las "políticas de la tierra" en el oeste de la meseta del Duero». En Díaz, Pablo de la Cruz; Luis Corral, Fernando y Martín VIso, Ińaki (eds.). El historiador y la sociedad. Homenaje al profesor José María Minguez. Salamanca: Ediciones Universidad de Salamanca, 2013, pp. 39-52. 
MARÍA PÉREZ RODRÍGUEZ

CASTROFROILA: LA REPRESENTACIÓN DEL PODER CENTRAL EN LA RIBERA DEL CEA

(SIGLOS X-XII)

naturaleza de los vínculos establecidos entre el poder central y los grupos magnaticios ${ }^{32}$. En este contexto el castillo de Castro Froila parece haber adquirido una relevancia espacial, puesto que no va a ser raro documentar la presencia de los monarcas en el lugar tal y como ya adelantamos en páginas precedentes. Desde este punto de vista, en el año 1057 los monjes del monasterio de Sahagún y Gutier Vélaz se presentan ante el rey Fernando I en Castro Froila como consecuencia del pleito que les enfrentaba en relación al lugar de Villada $^{33}$. La escena se repite en diversas ocasiones y, ya bajo el reinado de Alfonso VI, destaca el pleito que en el año 1091 oponía en este caso al abad del citado monasterio y al conde Martín Flaínez que actuaba en representación de los habitantes de Villavicencio, compareciendo los contendientes ante el rey de nuevo en Castro Froila ${ }^{34}$. Los ejemplos podrían multiplicarse, si bien cabe destacar cómo buena parte de ellos van a estar precisamente protagonizados por el monasterio de Sahagún. La explicación de tal hecho -y la de otros tantos de características similares que se reiteran a lo largo de la centuria ${ }^{35}$ habría de buscarse en la condición alcanzada por este cenobio como uno de los grandes propietarios señoriales de la zona y en su pretensión de extender su poder por nuevos sectores $^{36}$. No obstante, si Castro Froila asumió el papel de centro de representación regio en el arbitraje de los litigios señoriales, esta no va a ser la única función que se le pueda atribuir. La documentación hace posible asimismo observar cómo va a ser precisamente en este lugar donde se haga efectivo el cumplimiento de ciertas sentencias judiciales. El mejor ejemplo lo representa la condena a la que fue sometido un tal Domingo Quintilaz, acusado de haber robado un caballo a Anaya Vélaz, de manera que la pena impuesta al ladrón supuso su encarcelamiento in carcere in Castro Froila ${ }^{37}$. Estos datos aquí expuestos se complementan con otros tantos que vienen a revelar la elaboración y roboración de diversos diplomas reales en este mismo lugar ${ }^{38}$. Todos ellos han de interpretarse dentro

32 Los vínculos entre monarquía y poderes señoriales han sido analizados, por ejemplo, por autores como Escalona Monge o Álvarez Borge en los sectores castellanos. A sus obras nos remitimos: EscALONA Monge, Julio. "Misericordia regia, es decir, negociemos. Alfonso VII y los Lara en la Chronica Adefonsi imperatoris». En Alfonso, Isabel; Escalona, Julio y Martin, George (eds.). Lucha política. Condena y legitimación en la España medieval. Lyon: Ens Éditions, 2004, pp. 101-152; y Álvarez Borge, Ignacio. Cambios y alianzas. La politica regia en la frontera del Ebro en el reinado de Alfonso VIII de Castilla (1158-1214). Madrid: Consejo Superior de Investigaciones Científicas, 2008.

33 Illis ver, contra respondentibus, quia non iusserat et pro ista venerunt in presentia domni Fredenandi regis in Castro Froila. CDMS-II, doc. 588.

34 In voce de homines iam supradictos, contra abbatem supra taxatum in assercione et contemptione ante regem dominum Adefunsum in Castro Froila. CDMS-III, doc. 881.

35 En 1080 un nuevo pleito opone a Diego, abad de Sahagún, y a los descendientes de Gonzalo Fernández. Dos ańos más tarde Fromarico, abad del monasterio de Samos, y Ecta Goséndiz se querellan por el monasterio de Barja, presentándose en Castro Froila ante Alfonso VI. Gambra, Alfonso VI, docs. 69 y 75.

36 Según plantea Fernando Luis Corral, el cenobio intentaría expandir su dominio a costa de parcelas de jurisdicción que en realidad no le correspondían, en la medida en que los habitantes de Villavicencio solo se mostraban dependientes de Sahagún en virtud de las tierras que trabajaban. Una de las consecuencias de este proceso y de la conflictividad social generada sería la concesión del primer fuero de la villa precisamente en el año 1091. Luis Corral, Fernando. Villavicencio en la Edad Media. Poder y jurisdicción en los valles del Cea y del Valderaduey. Valladolid: Diputación de Valladolid, 2003, p. 113.

37 CDMS-II, doc. 725.

38 Se trataría, por ejemplo, de la donación realizada en el ańo 1099 por el rey Alfonso VI a favor de la sede episcopal de Burgos, a la que entrega el monasterio de Santa Eulalia de Muciéhar con sus pertenencias 
MARÍA PÉREZ RODRÍGUEZ

CASTROFROILA: LA REPRESENTACIÓN DEL PODER CENTRAL EN LA RIBERA DEL CEA

(SIGLOS X-XII)

del contexto político del momento y de los cambios promovidos por una autoridad central motivada, por un lado, por poner en marcha un mecanismo encargado de poner freno a la expansión señorial y, por otro, por mantener una constante negociación con los poderes de la zona. Desde este punto de vista se entendería la implantación de la tenencia como un nuevo sistema de gestión y administración territorial, percibida esta en un sentido ambivalente, como escenario en el que se entretejen y articulan las relaciones entre el poder central y los poderes locales ${ }^{39}$.

Este nuevo «modelo» de ordenación afectó por igual a la Ribera del Cea tal y como demuestran los documentos. En febrero del ańo 1102 se constata la presencia de Ero Gutiérrez en Castro Froila ${ }^{40}$ y meses más tarde, en abril, es Pelayo Xapiz quien asume el cargo de maiorino maiore de Castro Froila ${ }^{41}$. Una vez más la interpretación de estos acontecimientos debe ponerse en relación con las estrategias de poder desencadenadas entre señores y monarquía. Mediante la concesión de estos cargos el poder público buscaba una forma de garantizar su representación en la zona y al mismo tiempo de ganar unas fidelidades a todas luces necesarias para preservar su propia situación y estabilidad ${ }^{42}$, esencialmente en una zona fronteriza como era aquella que se abría entre el Cea y el Pisuerga. En efecto, una de las características que va a definir el desempeño de este cargo va a ser, tal y como ha señalado Álvarez Borge, la naturaleza temporal de estas concesiones ${ }^{43}$. De este modo, merinos y tenentes podían ser revocados de su cargo por la autoridad central que de este modo adquiría, al menos de forma teórica, cierto margen de control. Desde este punto de vista, de algún modo se puede afirmar que Castro Froila se convirtió en moneda de cambio, pero con capacidad de revertir en cualquier momento al monarca, quien de este modo intentaba asegurarse la lealtad de las aristocracias ${ }^{44}$.

(Facta autem hac testamenti serie sub era T C XXX VII, et noto die qui fuit IV nonas februarii, et eodem die in Castrofroyla roborata) y de la cesión que del monasterio de San Salvador de Villaverde realiza el mismo monarca en el año 1100 en este caso a favor de Sahagún (Facta hec carta in Castro Froila). Gambra, Alfonso VI, doc. 151 y CDMS-III, doc. 1.045, respectivamente.

39 Álvarez Borge, Cambios y alianzas, p. 242.

40 CDMS-III, doc. 1080.

$41 \quad$ Ibidem, doc. 1082.

42 Sobre el vínculo entre monarquía y nobleza en la zona remitimos al estudio de Luis CoRraL, Fernando. «Cambios de lealtades/cambios territoriales: una reflexión sobre las relaciones entre monarquía y nobleza castellano-leonesa en torno al tratado de Sahagún de 1158». En Ser Quijano, Gregorio del y MarTín Viso, Iñaki (eds.). Espacios de poder y formas sociales en la Edad Media. Estudios dedicados a Ángel Barrios. Salamanca: Ediciones Universidad de Salamanca, 2007, pp. 119-132.

43 Álvarez Borge, Cambios y alianzas, p. 242. Sobre estas cuestiones véase, además, Vital FernánDEZ, Sonia. Reino e Imperio: poder, negociación y articulación interior en época de Alfonso VII. Tesis doctoral inédita. Universidad de Salamanca, 2012.

44 Cuestiones similares han sido analizadas por Calderón Medina, para quien el cargo de tenente y su nombramiento como un acto condicionado por la voluntad regia iban a redundar en la creación de una relación de dependencia de la aristocracia respecto del poder del monarca. Calderón Medina, Inés. Cum magnatibus regni mei: la nobleza y la monarquía leonesa durante los reinados de Fernando II y Alfonso IX (11571230). Madrid: Consejo Superior de Investigaciones Científicas, 2012, p. 308. 
MARÍA PÉREZ RODRÍGUEZ

CASTROFROILA: LA REPRESENTACIÓN DEL PODER CENTRAL EN LA RIBERA DEL CEA

(SIGLOS X-XII)

\section{La tenencia de Castro Froila, ¿Un caso particular?}

Como hemos tenido ocasión de observar, Castro Froila aparece en los textos bajo el control de Ero Gutiérrez a comienzos del siglo XII. La nómina de tenentes asociados a este emplazamiento a lo largo de esta centuria va a ser, sin embargo, muy larga ${ }^{45}$. Así, vemos sucederse en el cargo a figuras como Osorio Martínez ${ }^{46}$, Ponce de Minerva ${ }^{47}$, Fernando Rodríguez el Castellano ${ }^{48}$ o García López ${ }^{49}$, entre otros. Casi todos ellos pertenecen o derivan de importantes familias aristocráticas que a lo largo de los siglos han ido definiendo su patrimonio en la Ribera del Cea e incluso en torno al propio Castro Froila. Como ejemplos contamos con información sobre las donaciones que Rodrigo y Osorio Martínez realizaron a favor del monasterio de Sahagún y que vienen a identificarse con las villas de Valdecéspedes y Villa Dot ${ }^{50}$, o las propiedades adquiridas por Ponce de Minerva en Mayorga y que más tarde su esposa, Estefanía Ramírez -ya viuda-, cedería al monasterio de Santa María de Benevívere ${ }^{51}$. En concreto, este personaje originario de la zona catalana se instala en Tierra de Campos dando lugar a una de las familias más notables del siglo XII. Al igual que su homónimo Ponce de Cabrera -también de origen catalán-, formaba parte del séquito que acompañaba a la futura esposa de Alfonso VII, Berenguela $^{52}$. Pronto el número de bienes en su haber aumentaría llegando a extenderse su patrimonio por el Páramo leonés ${ }^{53}$ y la Ribera del Cea ${ }^{54}$.

Estos mismos magnates, cuyas fidelidades serán la respuesta a las compensaciones regias, van a ser en gran medida los responsables de mantener o, por el contrario, modificar el tipo de relación con la autoridad central e, indirectamente, el contexto

45 Rodríguez Fernández, «Apuntes para la historia», pp. 325-332.

46 Fernández Flórez, José Antonio. Colección diplomática del monasterio de Sahagún (857-1300). Vol. $I V$. León: Centro de Estudios e Investigación San Isidoro, 1991, doc. 1244. (A partir de ahora CDMS-IV).

47 Ibidem, doc. 1280.

48 Rodríguez González, Ángel. El tumbo del monasterio de San Martín de Castañeda. León: Centro de Estudios e Investigación San Isidoro, 1973, doc. 63. (A partir de ahora TSMC).

49 Martínez, Martín. Cartulario de Santa María de Carracedo (922-1550). Vol. I. Ponferrada: Instituto de Estudios Bercianos, 1997, doc. 100. (A partir de ahora CSMC).

50 Escalona, Romualdo. Historia del Real Monasterio de Sahagún: sacada de la que dexó escrita el Padre Maestro Fr. Joseph Pérez, corregida y aumentada con varias observaciones históricas y cronológicas y con muchas memorias muy conducentes a la Historia General de España. Madrid: Joachín Ibarra, 1872, vol. II, ap. III, escrit. CL, p. 515. Sobre estos personajes resulta imprescindible el estudio realizado por Martínez SopenA, «El conde Rodrigo de León y los suyos», pp. 51-84.

51 Ego comitissa donna stephania una cum fliabus meis facimus kartam donationis deo et ecclesie beate marie de bene vivere... et de uno solare in maiorga super fontem de lasseo. FERnÁNDEz, Luis. Colección diplomática de la abadia de Santa María de Benevivere: Palencia (1020-1561). Madrid: Escuela Gráfica Salesiana, 1967, doc. 15. (A partir de ahora $C D M B$ ).

52 Barton, Simon. "Two Catalan magnates in the courts of the kings of León-Castile: the careers of Ponce de Cabrera and Ponce de Minerva re-examined». Journal of Medieval History, 1992, vol. 18, pp. 233-266.

53 Ego imperator Adefonsus tocius Hispaniae facio textum et scriptum firmissimum in perpetuum vobis Pontio de Minerba et uxori vestre domine Stephanie, de illa mea hereditate Sancti Petri de Paramom. CASADo Lobato, María Concepción. Colección diplomática del monasterio de Carrizo. León: Centro de Estudios e Investigación San Isidoro, 1983, doc. 27.

$54 C D M B$, doc. 15 . 
MARÍA PÉREZ RODRÍGUEZ

CASTROFROILA: LA REPRESENTACIÓN DEL PODER CENTRAL EN LA RIBERA DEL CEA

(SIGLOS X-XII)

político. Llegados a este punto cabe por tanto preguntarse cuál fue el alcance de la implantación de este nuevo sistema de organización administrativa por parte de la monarquía, sobre todo si consideramos que, por un lado, los nombramientos siguieron recayendo sobre grandes personalidades, magnates, algunos de los cuales ostentaban el título de $\operatorname{comes}^{55}$, y, por otro, que actos como la llamada desnaturalización y transferencia de fidelidades fueron relativamente habituales ${ }^{56}$, afectando también al núcleo que aquí estudiamos. Quizás el ejemplo más claro lo represente la figura de Fernando Rodríguez de Castro, conocido como "el Castellano» y tenente de este lugar en los ańos 1171 y $1172^{57}$, cuya actuación política quedó condicionada por sus propios intereses, hecho que le llevaría a moverse tanto a favor del monarca castellano como del leonés $s^{58}$. En este contexto se puede afirmar que el castillo de Castro Froila-Mayorga ${ }^{59}$, y con él su territorio y la capacidad jurisdiccional que se habría de ejercer sobre el mismo, quedó a disposición de los diversos tenentes que se suceden a lo largo del siglo XII. Este hecho no supuso, sin embargo, su desvinculación con el monarca tal y como se infiere de la serie de documentos que, aun de forma intermitente, se elaboran y roboran aquí entre los ańos 1142 y $1186^{60}$.

A la luz de los datos expuestos hasta el momento parece haber quedado claro que, al menos desde mediados del siglo xI, Castro Froila actuó como centro de representación de la autoridad central, tanto de forma directa como indirecta a través de los tenentes. Desde este punto de vista cabría la posibilidad de preguntarse si esta relación entre tenencia y

55 Comes Munniu in Maiorca, conf. (Ruiz Asencio, José Manuel y RuIz Albi, Irene. Colección documental del monasterio de San Pedro de Eslonza (912-1300). Vol. I. León: Centro de Estudios e Investigación San Isidoro, 2007, doc. 83. (A partir de ahora CDME); comes Fernandus, Majorica et Beneventum. CSMC, doc. 98). En otros casos, y aunque no consten como tales en la documentación, se sabe que ostentaban este cargo como sucedería con las figuras de Osorio Martínez o Ponce de Minerva. Vid. Torres Sevilla, Linajes nobiliarios de León y Castilla.

56 Sobre este proceso de desnaturalización remitimos al estudio de EsTEPA DíEz, Carlos. «Naturaleza y poder real en Castilla». En Jara, José Antonio; Martin, Georges y Alfonso, Isabel (eds.). Construir la identidad en la Edad Media. Poder y memoria en la Castilla de los siglos VII a XV. Cuenca: Ediciones de la Universidad de Castilla-La Mancha, 2010, pp. 163-181. Véanse también los análisis efectuados por MarTínez Sopena, Pascual. «Las villas del rey y las fronteras del reino (ca. 1158-1230)». En Jara, Martin, y Alfonso (eds.), Construir la identidad, pp. 105-143 y «El conde Rodrigo de León y los suyos»; y por LuIs CorraL, "Cambios de lealtades/cambios territoriales», especialmente pp. 126-131 y "Un castellano en la corte del rey Fernando: breves notas para el estudio de las relaciones monarquía/nobleza en el siglo XII». En DíAz, LUIS Corral y Martín Viso (eds.), El historiador y la sociedad, pp. 115-127.

57 Fernando Rodriguez en Mayorga y Bolaños (TSMC, doc. 63); Fernandus Rodriguiz in Maiorga et in Melgar de Suso (Domínguez Sánchez, Santiago. Colección documental de los monasterios de San Claudio de León, monasterio de Vega y San Pedro de las Dueñas. León: Centro de Estudios e Investigación San Isidoro, 2001, doc. 65.

58 Luis Corral, "Un castellano en la corte del rey Fernando».

59 La utilización de este doble topónimo responde a motivos meramente operativos sustentados en el hecho de que ya en la segunda década del siglo XII aparece este enclave citado en la documentación con el nombre de Mayorga. Si bien, estos aspectos se tratarán de forma más específica en el apartado correspondiente donde se atiende al nacimiento y origen del mismo.

60 Véase Herrero Jiménez, Mauricio. Colección documental del monasterio de Villaverde de Sandoval (1132-1500). León: Centro de Estudios e Investigación San Isidoro, 2003, doc. 2; y GonZÁLEz GonzÁLEZ, Regesta de Fernando II, pp. 347, 354, 466, 467, 469 y 510. 
MARÍA PÉREZ RODRÍGUEZ

CASTROFROILA: LA REPRESENTACIÓN DEL PODER CENTRAL EN LA RIBERA DEL CEA (SIGLOS X-XII)

Cuadro 1. Tenentes en Castrofroila-Mayorga durante el siglo XII ${ }^{6 \mathrm{I}}$.

\begin{tabular}{|c|c|c|c|}
\hline Tenencia & Tenente* & Ref. doc. & Texto \\
\hline Castro Froila & $\begin{array}{c}\text { Ero Gutiérrez } \\
(1102)\end{array}$ & CDMS-III, doc. 1080 & Ero Gutterriz in Castro Froila \\
\hline \multirow{12}{*}{ 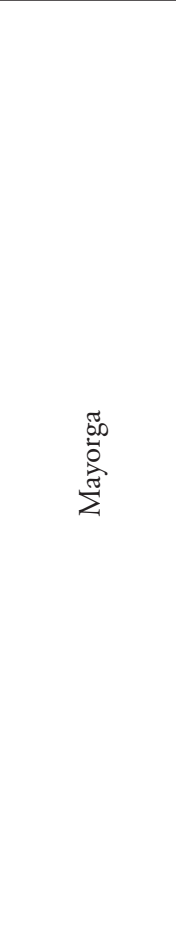 } & $\begin{array}{l}\text { Conde Munio } \\
(1126)\end{array}$ & $C D M E$, doc. 83 & $\begin{array}{l}\text { Comes Munniu in Maiorca, } \\
\text { conf. }\end{array}$ \\
\hline & $\begin{array}{c}\text { Pedro López } \\
(1130)\end{array}$ & $C D M G-I$, doc. 28 & Petro Lupiz in Maiorga \\
\hline & $\begin{array}{c}\text { Osorio Martínez } \\
(1131)\end{array}$ & CDMS-IV, doc. 1244 & Osorio Martiniz in Maiorga \\
\hline & $\begin{array}{c}\text { Conde Fernando } \\
(1140)\end{array}$ & CDMS-IV, doc. 1269 & $\begin{array}{c}\text { Fernando comite tenente } \\
\text { Maiorica et Valadolid }\end{array}$ \\
\hline & $\begin{array}{c}\text { Ponce de Minerva } \\
(1144)\end{array}$ & $C D M S-I V$, doc. 1280 & $\begin{array}{c}\text { Poncius de Minerua armiger } \\
\text { tenente Maiorga }\end{array}$ \\
\hline & $\begin{array}{c}\text { Fernando Rodríguez } \\
(1171)\end{array}$ & TSMC, doc. 63 & $\begin{array}{c}\text { Fernando Rodriguez en } \\
\text { Mayorga y Bolaños } \\
\end{array}$ \\
\hline & $\begin{array}{c}\text { Gonzalo Osorio } \\
(1175)\end{array}$ & TSMC, doc. 66 & $\begin{array}{c}\text { Gundisalvus Osoriiz tenente } \\
\text { Maiorga et Valderas }\end{array}$ \\
\hline & $\begin{array}{l}\text { Pedro Rodríguez y } \\
\text { Gutierre Rodríguez }\end{array}$ & $C D M S-I V$, doc. 1415 & $\begin{array}{c}\text { Petro Roderici et Guterrio } \\
\text { Roderici tenentibus Maioricam }\end{array}$ \\
\hline & $\begin{array}{c}\text { Fernando Gascón } \\
(1185)\end{array}$ & $\begin{array}{l}\text { González, J. Regesta } \\
\text { Fernando II, p. } 503\end{array}$ & F. Gascon in Maiorica \\
\hline & $\begin{array}{c}\text { Fernando Gutiérrez } \\
(1186)\end{array}$ & $C D M S-I V$, doc. 1424 & $\begin{array}{l}\text { Fernandus Guterii tenens } \\
\text { Maioricam, conf. }\end{array}$ \\
\hline & $\begin{array}{l}\text { Conde Fernando Ponce } \\
(1186)\end{array}$ & $\begin{array}{l}\text { González, J. Regesta } \\
\text { Fernando II, p. } 509\end{array}$ & Com. F. t. Maior. et Benev. \\
\hline & $\begin{array}{c}\text { García López } \\
(1187)\end{array}$ & $T S M C$, doc. 81 & $\begin{array}{c}\text { Tenente Garcia Lupi Maiorica } \\
\text { et Benevento }\end{array}$ \\
\hline
\end{tabular}

castillo mostró siempre una naturaleza semejante o, dicho de otro modo, si el desempeño de un cargo público, en tanto que su nombramiento recaía sobre el monarca, se hacía necesariamente efectivo desde un centro de poder directamente vinculado al monarca. Evidentemente la respuesta no es sencilla, ni mucho menos unívoca, en la medida en que son numerosos los factores a tener en cuenta. Entre ellos se hace necesario atender, por ejemplo, al origen mismo del castillo. En este sentido, algunas de las líneas de investigación centradas en el estudio de las estructuras de poder se han preocupado por investigar el carácter de muchos de estos centros. Este aspecto reviste mayor importancia de la que puede aparentar a simple vista, en la medida en que da fe de las relaciones entabladas entre los distintos grupos de poder. Las investigaciones

61 Se ha tomado como referencia el año en el que se recoge la primera mención documental. BuRón Castro, Taurino. Colección documental del monasterio de Gradefes. León: Centro de Estudios e Investigación San Isidoro, 1998-2000. (A partir de ahora CDMG-I). 
realizadas por Portela y Pallares ${ }^{62}$ para el sector gallego, y más en concreto para el señorío compostelano, a cuya cabeza se encontraba el obispo Gelmírez, constituyen una buena prueba de todo ello. Uno de los episodios más representativos protagonizados por este personaje lo encontramos precisamente en la pretensión del prelado de reconstruir la fortaleza de Oeste, situada en los límites de su señorío. Tal interés chocaría de frente con la negativa de Alfonso VI, quien mediante su prohibición intentaba evitar el excesivo fortalecimiento del representante de la sede episcopal. Evidentemente las lecturas que se pueden realizar de un acontecimiento tan interesante como este son múltiples y las conclusiones diversas. Por un lado, está revelando con gran claridad el grado de poder alcanzado por el obispo -quien en última instancia, y desoyendo la prohibición regia, pondría en marcha las obras de reconstrucción de la fortificación-; por otro, evidencia el interés por hacerse con el control de estos castillos como centros de poder especialmente aptos para afianzar y mejorar el posicionamiento y estabilidad política de quienes en ellos se hallaban representados. Este es el escenario en el que deben valorarse las pugnas habidas entre Gelmírez y la reina Urraca por hacerse con semejante control. Todo ello prueba el estado de constante reequilibrio y tensión en el que llegaron a verse inmersas no solo las distintas facciones aristocráticas o los representantes de destacadas parentelas, enfrentadas entre sí por el engrandecimiento de sus dominios y de su poder, sino también la «rivalidad» habida entre estos grupos señoriales y la autoridad central. Finalmente, todos estos acontecimientos facilitan la comprensión de las distintas medidas y mecanismos a los que la propia autoridad central se vería obligada a recurrir para paliar el impulso y desarrollo señorial. En cualquier caso la conclusión de los autores en relación a la autoría de los centros fortificados parece clara. Para Portela y Pallares, esta poco tiene que ver con la propiedad privada, pues, muy al contrario, se encuentra vinculada al ejercicio del poder público ${ }^{63}$.

Para la zona castellana destacan los análisis emprendidos por Vázquez Álvarez, quien, en base a una metodología fundamentada en los estudios toponímicos, ha procedido a la definición de dos categorías tipológicas en relación a la naturaleza de las fortificaciones. La conclusión extraída no ha sido otra que la coexistencia de estructuras cuya fundación ha sido promovida por la monarquía con aquellas emanadas de actividades particulares ${ }^{64}$. A partir de los postulados propuestos por este autor, y siempre tomando en consideración la variedad de situaciones que pueden observarse, Álvarez Borge ha planteado para la zona de frontera del Ebro la existencia de una serie de castillos que no se hallaban sujetos al control regio. Se trataría de fortalezas seńoriales en las que ocasionalmente se documentaría la presencia de tenentes o alcaldes regios, hecho que vendría a justificar, por un lado, el vínculo que a veces se establece entre este tipo de centros y el sistema de tenencias y, por otro, la idea de que tenencia y señorío no eran realidades tan dispares ${ }^{65}$.

62 Portela, Ermelindo y Pallares, María Carmen. «De la fundación de los castillos en el tiempo y el espacio de Diego Gelmírez». En Díaz, Luis Corral y Martín Viso (eds.), El historiador y la sociedad, pp. 189-204.

\footnotetext{
63 Ibidem.

64 Vázquez Álvarez, «Castros, castillos y torres en la organización», pp. 351-374.

65 Álvarez Borge, Cambios y alianzas, especialmente pp. 269-279.
} 
MARÍA PÉREZ RODRÍGUEZ

CASTROFROILA: LA REPRESENTACIÓN DEL PODER CENTRAL EN LA RIBERA DEL CEA

(SIGLOS X-XII)

Finalmente, en Cataluña parece existir una mayor aproximación a las formas vigentes en países como Italia o Francia, donde la relación entre castillos y fundaciones señoriales se encuentra sobradamente demostrada ${ }^{66}$. La situación de los castells termenats en el condado catalán ha sido investigada por Batet i Company, quien ha insistido en el papel de los mismos como «instruments politics, els instruments d'un poder que necesita expresar-se contundentment ${ }^{67}$. En lo que a nuestra zona se refiere, parece haber quedado claro ya el carácter público que, al menos desde la mitad del siglo xI, caracterizó al castillo de Castro Froila. En este caso no contamos, efectivamente, con ningún tipo de información de carácter documental que nos haya permitido siquiera pensar en una construcción surgida por iniciativa aristocrática.

Como puede observarse, los mecanismos que regularon la definición del poder y sus bases de representación resultaron altamente heterogéneos y fuertemente influenciados tanto por el propio desarrollo político como por las realidades específicas de cada zona. $\mathrm{Al}$ menos esta es la imagen que se extrae de la mayor de las investigaciones efectuadas ${ }^{68}$. No obstante, de un modo u otro la dinámica que subyace en todos estos acontecimientos es prácticamente similar: la movilización del poder señorial con la intención de mejorar su situación y estatus y la necesidad, por parte de la monarquía, de mantener el equilibrio y garantizarse los apoyos y fidelidades de los que depende la propia política regia. De la capacidad de negociación de unos y otros dependerá el mayor o menor éxito para alcanzar tales objetivos.

\section{De Castro Froila a Mayorga: el nacimiento de la villa regia}

En las primeras décadas del siglo XII el enclave de Castro Froila comienza a experimentar cierta decadencia, posiblemente condicionada por todas las transformaciones que operaron a nivel político durante la centuria previa y de las que venimos dejando constancia. En el año 1117 aparece citado por primera vez el lugar de Mayorga ${ }^{69}$, desapareciendo Castro Froila de la documentación en torno a $1130^{70}$ y siendo sus funciones políticas asumidas por este nuevo centro de $\operatorname{poder}^{71}$, cuya localización distaría muy poco del emplazamiento en el que se alzaba el antiguo castro ${ }^{72}$. El enclave en cuestión se encuentra ocupado por el actual núcleo urbano de Mayorga de Campos, por lo que

66 Remitimos a la nota 4.

67 Batet i Company, «La marca encastellada?», p. 345.

68 Estas cuestiones son perfectamente transferibles a otras regiones extrapeninsulares, y no cabe duda de que su estudio puede aportarnos datos muy interesantes al respecto. Ante la imposibilidad de plantear aquí semejante análisis comparativo, remitimos a los ejemplos planteados para Italia.

69 Villa Alba iuxta Maioricam. Martín López, María Encarnación. Patrimonio cultural de San Isidoro de León. Documentos de los siglos X-XIII. León: Universidad de León, 1995, doc. 16. Por su parte, Martínez Sopena retrasa la fecha de aparición documental de Mayorga hasta el año 1126. Martínez Sopena, La Tierra de Campos occidental, p. 66.

70 Ibidem, p. 141.

71 Gutiérrez González, Fortificaciones y feudalismo, p. 338.

72 Esto sería así siempre y cuando aceptásemos la propuesta de Gutiérrez González, quien -recordemos- situaba Castro Froila en el Teso Miravete, a escasa distancia de Mayorga. 
resulta muy complejo emprender actuaciones arqueológicas que deparen vestigios de especial interés. A pesar de todo ha sido posible documentar ciertos restos que avalan la ubicación de la fortaleza medieval emplazada en la parte alta de la ladera. Se trataría de la muralla, realizada con cal y canto, de la que se conserva un lienzo, que se dibuja en curva para adaptarse a la disposición natural del terreno, de unos 8 metros de longitud por 2 de grosor y 3 de altura ${ }^{73}$. La complejidad en este caso estriba en la estimación del origen de dicha fortificación, para la que de nuevo no parece existir unanimidad. Martínez Sopena parece ser el único autor que sostiene que se trataría de los restos de la fortaleza plenomedieval, mientras que Mañanes, Valbuena y Alonso o Gutiérrez González opinan que nos encontraríamos ante el castillo que en el siglo xv mandó construir el conde de Benavente ${ }^{74}$.

En cualquier caso, e independientemente de cuál fuese su situación original, de lo que no cabe duda, a la luz tanto de las fuentes escritas como materiales, es que Mayorga albergaría un centro fortificado que poco a poco iría reemplazando al antiguo castro y desde el que se ejercería el control del territorio que se había ido gestando a lo largo de los siglos precedentes y de las unidades de población que en él se encontraban integradas. Así sucedería con las villas de Petra Fita, Villa Famete, Villalba de la Loma, San Martín, San Jorge, Oteruelo, Siero, Sahelices, Villa Dot, Valdunquillo y Villa La Maya ${ }^{75}$, lugares que han quedado en su mayoría despoblados y cuya huella ha perdurado hasta nuestros días a través de la microtoponimia y ocasionalmente de algún que otro vestigio material ${ }^{76}$. Este sería el caso de Caño Siero -donde han aparecido restos constructivos y cerámicos cuyas características han llevado a datarlos en época medieval- o del lugar de San Martín, identificado con la villa y monasterio de San Martín del Río, citados en el año 1108 y donde se han documentado diversos focos con restos de lo que podría ser un edificio cultual y una necrópolis ${ }^{77}$.

Todas estas modificaciones deben, no obstante, entenderse a la luz de los acontecimientos que dominan la realidad política del momento y que vendrán definidos tanto por

73 Inventario Arqueológico de la Provincia de Valladolid. Municipio de Mayorga.

74 Gutiérrez González, Fortificaciones y feudalismo, p. 341.

75 Vid. Martínez Sopena, La Tierra de Campos occidental, p. 123. Estas villas son reconocidas por Martínez Sopena para los siglos x y xII, si bien el número de núcleos aumenta con posterioridad, y centros que hasta este momento habían actuado como ejes de control de su propio territorio -como Castrobol- quedan inmersos en estado de decadencia, pasando a depender de Mayorga. Sobre este último planteamiento véase RodríguEz Fernández, "Apuntes para la historia», p. 320. Por su parte, González Ramos, en su obra sobre las villas regias en el reino de León, efectúa un interesante estudio sobre el alfoz de Mayorga y las villas que formarían parte del mismo. El autor, que expone los datos en sendos mapas, realiza una comparación entre los núcleos que integrarían el territorio de Castro Froila y el alfoz de Mayorga, al tiempo que plantea la presunta localización de estos. Véase González Ramos, José Ignacio. Las villas reales en el reino de León. Los procesos pobladores de Fernando II y Alfonso IX en la Tierra de León. León: Centro de Estudios e Investigación San Isidoro, 2008; sobre la proyección territorial de Mayorga véanse especialmente pp. 268-278. Los mapas en pp. 718-719.

76 La revisión del inventario arqueológico de Valladolid -y en este caso concreto del municipio de Mayorga- permite concluir la existencia de algunos de estos despoblados citados en la documentación.

77 Se trata de fragmentos cerámicos torneados, de coloración grisácea evidenciando su cocción reductora y decoración a peine, así como restos constructivos como tégulas, tejas curvas, ladrillos, piedras areniscas y algunas calizas. Remitimos a la información proporcionada por el Inventario Arqueológico de la Provincia de Valladolid. Municipio de Mayorga. 
MARÍA PÉREZ RODRÍGUEZ

CASTROFROILA: LA REPRESENTACIÓN DEL PODER CENTRAL EN LA RIBERA DEL CEA

(SIGLOS X-XII)

la separación de los reinos de León y Castilla como por la fundación de las villas regias como mecanismo de reordenación del patrimonio regio. Justamente, tras la muerte de Alfonso VII se hizo efectiva la división del reino entre sus sucesores, Fernando II y Sancho III, iniciándose de este modo el enfrentamiento entre ambos. Este estado de tensión originado por el conflicto facilitó la expansión de los poderes nobiliarios, que aprovecharían la situación de inestabilidad generada para expandir sus dominios ${ }^{78}$. La frontera entre ambas entidades adquiría el carácter de una «franja geográfica» difusa, cambiante y fuertemente condicionada -como hemos tenido ocasión de comprobar- por la tendencia de las aristocracias a prestar sus servicios a un monarca u otro siempre en función de sus intereses ${ }^{79}$ y de las posibilidades de ascender y promocionar en su carrera política. En este contexto se hará frecuente la sucesión de pactos y tratados de paz encaminados a garantizar el acuerdo y la estabilidad en ambos reinos hasta alcanzar su unión definitiva, ya bajo el reinado de Fernando $\mathrm{III}^{80}$. En virtud de este reparto y de la división a la que se vio sometido el reino, Mayorga quedaba en manos del rey leonés Fernando II y, sin duda, la significación y peso alcanzado por este centro político se haría evidente en la actitud y pretensión del monarca por conservarlo para sí. Allí lo encontraremos en dos ocasiones en el año 1158. En primer lugar como consecuencia de la donación realizada por el monarca a Ordońo Ordóńez ${ }^{81}$ y, en segunda instancia, con motivo de la cesión a favor del monasterio de Santa María de Villanueva de Oscos, al que concede la jurisdicción sobre los moradores del lugar ${ }^{82}$.

Pero, es más, los enclaves de frontera adquieren en estos momentos renovada relevancia en la medida en que su control -y por tanto también el de su tenente- suponía el control de estos espacios fronterizos y de los importantes territorios localizados entre el Cea y Pisuerga. Los castillos aquí ubicados van a actuar, como si de piezas de un gran tablero de ajedrez se tratase, de prendas encaminadas a garantizar el respeto y cumplimiento de los pactos establecidos entre los distintos monarcas. Los ejemplos son diversos ${ }^{83}$ : Melgar, Castrotierra, Peñafiel, Siero y Portilla, son algunos de los núcleos cedidos por el rey Fernando II como símbolo de fidelidad, al mismo tiempo que el rey castellano hace entrega de Santibáñez de Resova, San Román de Entrepeñas, Saldaña, Cea y Cubillas ${ }^{84}$.

Puede observarse que en esta relación de entregas no aparece recogido el nombre de Mayorga, lo que debe considerarse un síntoma más de la relevancia que el lugar tuvo para

78 Véase Luis Corral, Villavicencio en la Edad Media, especialmente la primera parte, pp. 21-83 y 148.

79 Estas cuestiones se aprecian bien en el estudio de Luis Corral, «Cambios de lealtades/cambios territoriales», pp. 119-132.

80 En relación a estos aspectos remitimos a la ya citada obra de MARTínez SopenA, "Las villas del rey».

81 F. C. apud Maiorgam VII kalendarum ianuarii sub era MCLXXXXVI anno quo obiit. GonZÁlez GonzÁlez, Regesta de Fernando II, p. 354.

82 Ibidem, p. 347.

83 Sobre la entrega de castillos, véase Calderón Medina, Cum magnatibus regni mei, pp. 420-424.

84 Et ego Rex Fernandus mitto V castella in fidelitate in manu Petri Ferrandez, magristri militie Sancti Jacobi, et in manu Petri de Areis, prioris Hospitaleis, videlicet: Melgar, Castrum terre, Pennan fidelem cum Penna Braol et cum Penna destal pro uno castello, Siero, Portellam, pro tenenda et obseruanda pace inter nos et filios nostros et filias in perpetuum... Similiter Ego Adefonsus Rex Castelle mitto V castella in fidelitate in manu Petri Ferrandez, magristri militie Sancti Jacobi, et in manu Petri de Areis, prioris Hospitaleis, videlicet: Scm. Iohannem de Resoa, Scm. Romanum de la Penna, Saldaniam, Ceiam, Covellas, pro tenenda et observanda pace. Ibidem, doc. 40, pp. 299-304. 
MARÍA PÉREZ RODRÍGUEZ

CASTROFROILA: LA REPRESENTACIÓN DEL PODER CENTRAL EN LA RIBERA DEL CEA

(SIGLOS X-XII)

el rey y en el que nuevamente aparece presente en diversas ocasiones a lo largo del año $1180^{85}$. Pero quizás el síntoma más representativo de este interés regio fue la fundación de la villa regia y su dotación foral en el año 1181, dando respuesta a un programa de reformas mucho más extenso y cuya amplitud parecía rebasar incluso los límites peninsulares $^{86}$. En términos generales se trata de un aspecto que ha sido bien analizado por diversos autores y para el que contamos con interesantes estudios y aportaciones ${ }^{87}$. Tanto el nacimiento de esta villa regia como las numerosas fundaciones que en el siglo XII se están llevando a cabo al norte del Duero, puede considerarse como un nuevo mecanismo puesto en marcha por la monarquía. Semejante fenómeno comenzó a hacerse evidente ya a finales del siglo $\mathrm{XI}^{88}$, aunque alcanzaría su máxima expresión en las décadas finales del XII, coincidiendo en gran medida con las etapas de recrudecimiento del conflicto bélico entre ambos reinos ${ }^{89}$. A través de dicho mecanismo se pretendía garantizar y asegurar el control de estos centros y de sus alfoces dependientes, cuyo crecimiento se realizaría a costa del patrimonio regio ${ }^{90}$.

85 Ibidem, pp. $466-467$ y 469.

86 Martínez Sopena atribuye estas fundaciones a un fenómeno de reordenación gradual que implicó al poder regio a nivel europeo. Martínez Sopena, Pascual. «Las villas nuevas leonesas, el poder del rey y los otros señoríos (1230-1350)». En El Condado de Benavente. Relaciones hispano-portuguesas en la Baja Edad Media. Actas del Congreso hispano-luso del VI Centenario del Condado de Benavente. Benavente 22 y 23 de octubre de 2008. Benavente: Centro de Estudios Benaventanos Ledo del Pozo, 2000, p. 13.

87 Sobre las villas regias ténganse en cuenta los estudios realizados por autores como Monsalvo ANTón, José María. «Los territorios de las villas reales de la vieja Castilla, siglos XI-XIV: antecedentes, génesis y evolución (estudio a partir de una docena de sistemas concejiles entre el Arlanza y el alto Ebro)». Studia Historica. Historia Medieval, 1999, vol. 17, pp. 15-86; y «Concejos castellano-leoneses y feudalismo (siglos XI-XIII). Reflexiones para un estado de la cuestión». Studia Historica. Historia Medieval, 1992, vol. 10, pp. 202-243. Para el estudio de los fueros remitimos a los análisis efectuados por Rodríguez Fernández, Justiniano. «El fuero de Mayorga de Campos». Archivos Leoneses, 1989, vol. 85-86, pp. 99-128; «El fuero de Laguna de Negrillos». Archivos Leoneses, 1976, vol. 59-60, pp. 291-316; y «Los fueros de Peñafiel (Valladolid) y su notación histórica». Anuario de Estudios Medievales, 1987, vol. 17, pp. 35-42.

88 Martínez Sopena, «Las villas del rey», p. 129.

89 Ello se desprende de los numerosos tratados que tuvieron lugar desde mediados del siglo xiI: el de Sahagún (1158), Medina de Rioseco (1181), Fresno Lavandera (1183) y Tordehumos (1194). LuIs CoRRAL, Villavicencio en la Edad Media, pp. 27-73. La relevancia de estas fundaciones en espacios de frontera y el incremento cuantitativo de las mismas en relación a la defensa de ciertos límites espaciales sujetos a disputas entre distintos reinos han sido señalados en Martínez Sopena, Pascual et ál. «Las "villas nuevas" del norte del Duero: de la Rioja al Bierzo (siglos XII-XIII)». En Martínez Sopena, Pascual y Urteaga, Mertxe (eds.). Las villas nuevas medievales del suroeste europeo. De la fundación medieval al siglo XXI. Análisis histórico y lectura contemporánea. Actas de las Jornadas Interregionales de Hondarribia (16-18 noviembre 2006). Boletín Arkeolan, vol. 14. Centro de Estudios e Investigación Histórico-Arqueológicas, 2006, p. 220.

90 Un buen ejemplo lo constituyen las donaciones realizadas por Fernando II a favor del concejo de Benavente, haciendo efectiva la entrega de los territorios de Vidriales, Tera y Carballeda y garantizando además la expansión del alfoz benaventano. Cartam facio donationis toto concilio de Benevento... de istis meis hereditatibus quas dono et semper concedo pro alfoz de Benevento. Do videlicet Vidriales, Teyram et Carvaledam, cum omnibus directuris et pertinenciis suis. Martínez Sopena, Pascual; Aguado Seisdedoos, Vidal y González Rodríguez, Rafael. Privilegios reales de la villa de Benavente (siglos XII-XIV). Benavente: Centro de Estudios Benaventanos Ledo del Pozo, 1996, doc. 2. Téngase en cuenta que estas concesiones, realizadas en 1181, vienen a coincidir con la dotación foral de Mayorga, lo que evidencia la actividad desplegada por el monarca leonés. 
MARÍA PÉREZ RODRÍGUEZ

CASTROFROILA: LA REPRESENTACIÓN DEL PODER CENTRAL EN LA RIBERA DEL CEA

(SIGLOS X-XII)

Bajo esta empresa subyace, por tanto, una verdadera reestructuración de los modelos de poblamiento, gestión y administración territorial vigentes hasta ese momento ${ }^{91}$. Transformación que dará como resultado la aparición de nuevos órganos de gobierno encargados de asumir estas funciones: los concejos $^{92}$, cuya regulación interna quedaba recogida en los textos forales y cartas pueblas, a través de los que se dictaminaban las relaciones habidas entre los habitantes de la villa, entre esta y su territorio y los vínculos gestados entre los concejos y el monarca ${ }^{93}$.

La huella de todos estos hechos y de las pretensiones del poder central quedó plasmada, a nivel material, en la presencia del castillo y del recinto amurallado encargado de rodear y proteger la villa ${ }^{94}$. Según estima Martínez Sopena, ambos se convertirían en los elementos más significativos desde el punto de vista morfológico ${ }^{95}$, y todavía hoy en día es posible contemplar alguno de estos vestigios, como sucedería con la denominada Puerta del Arco, encargados de fosilizar y testimoniar el pasado histórico de Mayor$\mathrm{ga}^{96}$. A pesar de la controversia desatada entre historiadores y arqueólogos sobre el origen de la fortaleza y su ubicación original, de lo que no hay duda, a la luz de los testimonios documentales y materiales disponibles, es de su existencia y del importante papel que esta desempeńó durante la Edad Media al formar parte, junto a otras tantas villas, de un programa político nacido al amparo del feudalismo y de sus juegos de poder.

Se podría afirmar, para concluir, que de todos los centros de poder que se pueden identificar en la Ribera del Cea posiblemente sea el de Castro Froila-Mayorga el que manifieste de forma más clara y precisa su relación con la autoridad central, vínculo que a partir de las fuentes documentales podemos confirmar al menos para los siglos XI y XII.

El propio topónimo del enclave ha llevado a ciertos autores a pensar en su temprana asociación con algún personaje destacado de la zona. Es cierto que no sabemos nada de este Froila, y que rastrearle a través de la documentación resulta prácticamente imposible, pero, como se ha estimado para otros casos presentes también en la Ribera del Cea, pudo haberse tratado de un gran propietario que incluso podría haber mantenido algún tipo de contacto directo con el monarca o la corte regia, aunque hoy por hoy no es posible constatar este hecho. En cualquier caso este individuo habría sido el encargado de asegurar la articulación del territorio y del poblamiento desde este centro que, finalmente, terminaría por asumir su nombre.

91 Véase Martínez Sopena et ál., «Las "villas nuevas" del norte del Duero", pp. 221-222.

92 La bibliografía existente sobre el tema es abundante. Véase, por ejemplo, Martínez Sopena, Pascual. «Las pueblas reales de León y la defensa del Reino en los siglos Xir y XIII. En Ladero Quesada, Miguel Ángel (coord.). Castillos medievales del Reino de León. Madrid: Hullera Vasco-Leonesa, 1989, pp. 113-138. Para Monsalvo Antón dominio y jurisdicción regios serán transferidos después de los siglos x y xI al concejo. Monsalvo Antón, «Los territorios de las villas reales», p. 23.

93 Martínez Sopena, Pascual. «Los concejos, la tradición foral y la memoria regia en Castilla y León». En Martínez Sopena, Pascual y Rodríguez López, Ana (eds.). La construcción medieval de la memoria regia. València: Universitat de València, 2011, p. 138.

94 La normativa en relación al proceso de construcción y mantenimiento del castillo queda recogida en el propio fuero. Véase RodríGuez Fernández, «El fuero de Mayorga», pp. 108-118.

${ }_{95}$ Martínez Sopena, La Tierra de Campos occidental, p. 167.

96 Según el estudio realizado por Gutiérrez González, no se conservan en la actualidad ni restos del castillo plenomedieval ni de la muralla, quedando estos relegados a la ya citada Puerta del Arco. GutiérRez GonZÁLEZ, Fortificaciones y feudalismo, p. 339. 
MARÍA PÉREZ RODRÍGUEZ

La primera mención con la que contamos para Castro Froila se remonta al siglo IX y, a partir de la misma, autores como Gutiérrez González se han mostrado partidarios de atribuirle a este lugar una función política de forma tan temprana. No obstante, no es hasta el siglo XI cuando la documentación comienza a revelar la asimilación por parte de este núcleo de ciertas atribuciones estrechamente vinculadas a la presencia del monarca. Todas estas funciones han sido analizadas a lo largo de las páginas precedentes, por lo que no estimamos oportuno profundizar e insistir más en ellas. No podemos pasar por alto, sin embargo, que algunas de estas funciones revelan con claridad el panorama político de los siglos XI y XII y las paulatinas transformaciones experimentadas por este, sobre todo a partir de la implantación de la dinastía navarra en el reino leonés (luego castellano-leonés) bajo la figura de Fernando I, de cuya presencia ya tenemos constancia en Castro Froila.

Una de las principales transformaciones impulsadas por este monarca y continuada por sus sucesores, fue la puesta en marcha de un nuevo modelo de gestión y administración territorial. Entre los cambios propiciados por el poder central destacó la creación de nuevas marcas administrativas a cuyo cargo se encontraban los tenentes, delegados regios cuyo nombramiento recaía sobre el propio monarca, en un intento de mitigar el carácter hereditario que durante la fase precedente habían ido asumiendo otros nombramientos y dignidades. Las tenencias actuaban de este modo como monedas de cambio, en la medida en que a través de ellas el rey recompensaba a los miembros de determinados grupos aristocráticos, al mismo tiempo que se aseguraba -al menos desde un plano teórico-sus apoyos, tan necesarios para garantizar su propia estabilidad.

Todas estas transformaciones se hicieron evidentes también en Castro Froila, que ya a comienzos del siglo XII aparece citado en las fuentes como tenencia, aunque uno de los cambios más representativos a los que se vio sometido este centro fue su progresiva sustitución por un nuevo núcleo de poder: Mayorga, que poco a poco iría asimilando sus funciones. Su emplazamiento se hallaría relativamente cercano al Teso Miravete, lugar en el que según algunos autores se alzaba la antigua fortificación de Castro Froila. En cualquier caso, su ubicación era estratégica y el lugar entró a formar parte de la red de fortificaciones que, jalonando el río Cea, favorecían la defensa de la línea fronteriza abierta entre los reinos de León y Castilla, divididos y enfrentados desde la muerte de Alfonso VII.

Ante este panorama de conflicto casi constante, y a pesar de la firma de diversos tratados encaminados a asegurar paz y estabilidad, la conservación de los núcleos fortificados de la zona resultaba esencial por parte de ambos reyes. Los castillos eran piezas importantes del juego y servían para garantizar el cumplimiento de los pactos establecidos. Pero entre la nómina de fortificaciones puestas en juego no figuraba Mayorga, donde a finales del siglo XII vemos de nuevo presente a Fernando II, rey de León, quien en el año 1181 hace de este lugar una villa regia, dotándola de fuero y procediendo de este modo a reestructurar y reorganizar el realengo. En realidad, esta acción formaba parte de un proyecto político mucho más amplio, uno de cuyos resultados sería precisamente la paulatina asimilación de funciones y competencias por parte de los concejos como nuevos órganos de gobierno, todo ello a favor de una regeneración de los modelos administrativos hasta entonces vigentes. El papel desempeñado por Castro Froila-Mayorga no fue 
MARÍA PÉREZ RODRÍGUEZ

CASTROFROILA: LA REPRESENTACIÓN DEL PODER CENTRAL EN LA RIBERA DEL CEA

(SIGLOS X-XII)

ni más ni menos importante que el desempeñado por otros muchos centros de carácter fronterizo, pero toda su trayectoria, la que hoy intentamos recrear y comprender a partir de los documentos y restos materiales, no es más que la evidencia del complejo panorama político que caracterizó al periodo medieval.

\section{REFERENCIAS BIBLIOGRÁFICAS}

Álvarez Borge, Ignacio. Cambios y alianzas. La politica regia en la frontera del Ebro en el reinado de Alfonso VIII de Castilla (1158-1214). Madrid: Consejo Superior de Investigaciones Científicas, 2008.

Barton, Simon. «Two Catalan magnates in the courts of the kings of León-Castile: the careers of Ponce de Cabrera and Ponce de Minerva re-examined». Journal of Medieval History, 1992, vol. 18, pp. 233-266.

Batet i Company, Carolina. "La marca encastellada? Castells i pautas d'assentament a la Marca del Comtat de Barcelona (segles X-XI)». Afers, 1995, vol. 10, n. ${ }^{\circ} 21$, pp. 341-360.

Burón Castro, Taurino. Colección documental del monasterio de Gradefes. León: Centro de Estudios e Investigación San Isidoro, 1998-2000.

Calderón Medina, Inés. Cum magnatibus regni mei: la nobleza y la monarquía leonesa durante los reinados de Fernando II y Alfonso IX (1157-1230). Madrid: Consejo Superior de Investigaciones Científicas, 2012.

Carrera de la Red, Fátima. Toponimia de los valles del Cea, Valderaduey y Sequillo. León: Institución Fray Bernardino de Sahagún de la Excma. Diputación Provincial, 1988.

Carvajal Castro, Álvaro y Martín Viso, Iñaki. «Historias regionales de la repoblación: los reyes asturleoneses y las "políticas de la tierra" en el oeste de la meseta del Duero». En Díaz, Pablo de la Cruz; Luis Corral, Fernando y Martín Viso, Ińaki (eds.). El historiador y la sociedad. Homenaje al profesor José María Minguez. Salamanca: Ediciones Universidad de Salamanca, 2013, pp. 39-52.

Casado Lobato, María Concepción. Colección diplomática del monasterio de Carrizo. León: Centro de Estudios e Investigación San Isidoro, 1983.

Cavero Domínguez, Gregoria y Martín López, Encarnación. Colección documental de la Catedral de Astorga. Vols. I y II. León: Centro de Estudios e Investigación San Isidoro, 1999.

Domínguez Sánchez, Santiago. Colección documental de los monasterios de San Claudio de León, monasterio de Vega y San Pedro de las Dueñas. León: Centro de Estudios e Investigación San Isidoro, 2001.

Escalona Monge, Julio. «Misericordia regia, es decir, negociemos. Alfonso VII y los Lara en la Chronica Adefonsi imperatoris». En Alfonso, Isabel; Escalona, Julio y Martin, George (eds.). Lucha politica. Condena y legitimación en la España medieval. Lyon: Ens Éditions, 2004, pp. 101-152.

Escalona, Romualdo. Historia del Real Monasterio de Sahagún: sacada de la que dexó escrita el Padre Maestro Fr. Joseph Pérez, corregida y aumentada con varias observaciones históricas y cronológicas y con muchas memorias muy conducentes a la Historia General de España. Madrid: Joachín Ibarra, 1872.

Estepa Díez, Carlos. «Naturaleza y poder real en Castilla». En Jara, José Antonio; Martin, Georges y Alfonso, Isabel (eds.). Construir la identidad en la Edad Media. Poder y memoria en la Castilla de los siglos VII a XV. Cuenca: Ediciones de la Universidad de Castilla-La Mancha, 2010, pp. 163-181. 
MARÍA PÉREZ RODRÍGUEZ

CASTROFROILA: LA REPRESENTACIÓN DEL PODER CENTRAL EN LA RIBERA DEL CEA

Fernández Flórez, José Antonio. Colección diplomática del monasterio de Sahagún (857-1300). Vol. IV. León: Centro de Estudios e Investigación San Isidoro, 1991.

Fernández, Luis. Colección diplomática de la abadía de Santa María de Benevivere: Palencia (10201561). Madrid: Escuela Gráfica Salesiana, 1967.

Floriano, Antonio C. Diplomática española del periodo astur. Estudio de las fuentes documentales del Reino de Asturias (718-910). Vol. II. Oviedo: Diputación Provincial de Oviedo. Instituto de Estudios Asturianos, 1951.

Gambra, Andrés. Alfonso VI. Cancillería, curia e imperio. León: Centro de Estudios e Investigación San Isidoro, 1997-1998.

García Larragueta, Santos A. Colección de documentos de la catedral de Oviedo. Oviedo: [s. n.], 1962.

García Lobo, Vicente. Colección documental del monasterio de San Miguel de Escalada (940-1605). León: Centro de Estudios e Investigación San Isidoro, 2000.

GonzÁLEz DíEz, Emiliano. El régimen foral vallisoletano. Una perspectiva de análisis organizativo del territorio. Valladolid: Excma. Diputación Provincial de Valladolid, 1986, pp. 49-51 y 112-117.

González González, Julio. Regesta de Fernando II. Madrid: Consejo Superior de Investigaciones Científicas, Instituto Jerónimo Zurita, 1943.

GonzÁlez Ramos, José Ignacio. Las villas reales en el reino de León. Los procesos pobladores de Fernando II y Alfonso IX en la Tierra de León. León: Centro de Estudios e Investigación San Isidoro, 2008.

Gutiérrez González, José Avelino y Suárez Manjón, Patricia. «Castillos y fortalezas feudales en Asturias: metodología para su estudio». Territorio, Sociedad y Poder. Revista de Estudios Medievales, 2007, vol. 2, pp. 5-36.

Gutiérrez González, José Avelino. "Castillos y sistemas de defensa en los reinos de León y Castilla». En Iglesia Duarte, José Ignacio de la (coord.). II Semana de Estudios Medievales. Nájera del 5 al 9 de agosto de 1991. Logrońo: Instituto de Estudios Riojanos, 1992, pp. 31 48.

Gutiérrez GonzÁlez, José Avelino. «Excavaciones arqueológicas en el castillo de Curil (Peñaferruz, Gijón): campañas 1999-2002». En Excavaciones arqueológicas en Asturias: 1999-2002. Oviedo: Gobierno del Principado de Asturias, 2007, pp. 163-176.

Gutiérrez GonzÁlez, José Avelino. «Expansión y consolidación feudal del Reino de Asturias: las fortificaciones de Alfonso III en la montaña leonesa». En Homenaje a Juan Uría Ríu. Oviedo: Universidad de Oviedo, 1997, vol I, pp. 275-300.

Gutiérrez GonzÁlez, José Avelino. Fortificaciones y feudalismo en el origen y formación del Reino leonés (siglos IX-XIII). Valladolid: Secretariado de Publicaciones, 1995.

Herrero de la Fuente, Marta. Colección diplomática del monasterio de Sahagún, Vol. II. León: Centro de Estudios e Investigación San Isidoro, 1988.

Herrero Jiménez, Mauricio. Colección documental del monasterio de Villaverde de Sandoval (1132-1500). León: Centro de Estudios e Investigación San Isidoro, 2003.

Luis Corral, Fernando. «Cambios de lealtades/cambios territoriales: una reflexión sobre las relaciones entre monarquía y nobleza castellano-leonesa en torno al tratado de Sahagún de 1158». En Ser Quijano, Gregorio del y Martín Viso, Ińaki (eds.). Espacios de poder y formas sociales en la Edad Media. Estudios dedicados a Ángel Barrios. Salamanca: Ediciones Universidad de Salamanca, 2007, pp. 119-132.

Luis Corral, Fernando. Villavicencio en la Edad Media. Poder y jurisdicción en los valles del Cea y del Valderaduey. Valladolid: Diputación de Valladolid, 2003. 
MARÍA PÉREZ RODRÍGUEZ

CASTROFROILA: LA REPRESENTACIÓN DEL PODER CENTRAL EN LA RIBERA DEL CEA

(SIGLOS X-XII)

Martín López, María Encarnación. Patrimonio cultural de San Isidoro de León. Documentos de los siglos X-XIII. León: Universidad de León, 1995.

Martín Viso, Ińaki. «La monarquía asturleonesa en el Bierzo (siglos IX-X)». En ArízAga BoLumburu, Beatriz et ál. (eds.). Mundos medievales: espacios, sociedades y poder. Homenaje al profesor José Ángel García de Cortázar y Ruiz de Aguirre. Santander: PUbliCan, 2012, vol. I, pp. 733-746.

Martínez Sopena, Pascual et ál. «Las "villas nuevas" del norte del Duero: de la Rioja al Bierzo (siglos XII-XIII)». En Martínez Sopena, Pascual y Urteaga, Mertxe (eds.). Las villas nuevas medievales del suroeste europeo. De la fundación medieval al siglo XXI. Análisis histórico y lectura contemporánea. Actas de las Jornadas Interregionales de Hondarribia (16-18 noviembre 2006). Boletín Arkeolan, vol. 14. Centro de Estudios e Investigación Histórico-Arqueológicas, 2006, p. 220.

Martínez Sopena, Pascual. «El conde Rodrigo de León y los suyos: herencia y expectativa del poder entre los siglos x y xiI». En PAstor de Togneri, Reyna (ed.). Relaciones de poder, de producción y de parentesco en la Edad Media y Moderna: aproximación a su estudio. Madrid: Consejo Superior de Investigaciones Científicas, 1999, pp. 51-84.

Martínez Sopena, Pascual. «Las pueblas reales de León y la defensa del Reino en los siglos XII y XiII». En Ladero Quesada, Miguel Ángel (coord.). Castillos medievales del Reino de León. Madrid: Hullera Vasco-Leonesa, 1989, pp. 113-138.

Martínez Sopena, Pascual. «Las villas del rey y las fronteras del reino (ca. 1158-1230)». En Jara, José Antonio; Martin, Georges y Alfonso, Isabel (eds.). Construir la identidad en la Edad Media. Poder y memoria en la Castilla de los siglos VII a XV. Cuenca: Ediciones de la Universidad de Castilla-La Mancha, 2010, pp. 105-143.

Martínez Sopena, Pascual. «Las villas nuevas leonesas, el poder del rey y los otros señoríos (12301350)». En El Condado de Benavente. Relaciones hispano-portuguesas en la Baja Edad Media. Actas del Congreso hispano-luso del VI Centenario del Condado de Benavente. Benavente 22 y 23 de octubre de 2008. Benavente: Centro de Estudios Benaventanos Ledo del Pozo, 2000, p. 13 .

Martínez Sopena, Pascual. «Los concejos, la tradición foral y la memoria regia en Castilla y León». En Martínez Sopena, Pascual y Rodríguez López, Ana (eds.). La construcción medieval de la memoria regia. València: Universitat de València, 2011, p. 138.

Martínez Sopena, Pascual. «Parentesco y poder en León durante el siglo Xi. La "casata" de Alfonso Díaz». Studia Historica. Historia Medieval, 1987, vol. 5, pp. 33-88.

Martínez Sopena, Pascual. La Tierra de Campos occidental. Poblamiento, poder y comunidad en los siglos X a XIII. Valladolid: Institución Cultural Simancas, 1985.

Martínez Sopena, Pascual; Aguado Seisdedos, Vidal y González Rodríguez, Rafael. Privilegios reales de la villa de Benavente (siglos XII-XIV). Benavente: Centro de Estudios Benaventanos Ledo del Pozo, 1996.

Martínez, Martín. Cartulario de Santa Maria de Carracedo (922-1550). Vol. I. Ponferrada: Instituto de Estudios Bercianos, 1997.

MíngueZ Fernández, José María. «Pervivencia y transformaciones de la concepción y práctica del poder en el reino de León (siglos X-XI)». Studia Historica. Historia Medieval, 2007, vol. 25, pp. 56-57.

MíngueZ FernándeZ, José María. «Poderes locales en el espacio central leonés durante el periodo astur». En Fernández Conde, Francisco Javier y García de Castro Valdés, César (eds.). Territorio, Sociedad y Poder. Revista de Estudios medievales. Symposium Internacional Poder y Simbología en Europa, siglos VIII-X. Actas del Symposium Internacional convocado en Oviedo, 
MARÍA PÉREZ RODRÍGUEZ

CASTROFROILA: LA REPRESENTACIÓN DEL PODER CENTRAL EN LA RIBERA DEL CEA

(SIGLOS X-XII)

22-27 de septiembre del 2008. Oviedo: Ediciones Universidad de Oviedo, 2009, Anejo n. ${ }^{\circ} 2$, pp. 199-214.

Mínguez Fernández, José María. Colección diplomática del monasterio de Sahagún (siglos IX y X). León: Centro de Estudios e Investigación San Isidoro, 1976.

Monsalvo Antón, José María. «Concejos castellano-leoneses y feudalismo (siglos XI-XIII). Reflexiones para un estado de la cuestión». Studia Historica. Historia Medieval, 1992, vol. 10, pp. 202-243.

Monsalvo Antón, José María. «Los territorios de las villas reales de la vieja Castilla, siglos XI-XIV: antecedentes, génesis y evolución (estudio a partir de una docena de sistemas concejiles entre el Arlanza y el alto Ebro)». Studia Historica. Historia Medieval, 1999, vol. 17, pp. 15-86.

Nuccioti, Michele y Leporatti, Silvia. «Organizzazione del cantiere di una fortaleza rurale di XIII secolo: il caso di Montelaterone (Monte Amiata - Toscana)». Arqueología de la Arquitectura, 2003, vol. 2, pp. 255-265.

Portela, Ermelindo y Pallares, María Carmen. «De la fundación de los castillos en el tiempo y el espacio de Diego Gelmírez». En Díaz, Pablo de la Cruz; Luis Corral, Fernando y MarTín VIso, Iñaki (eds.). El historiador y la sociedad. Homenaje al profesor José María Minguez. Salamanca: Ediciones Universidad de Salamanca, 2013, pp. 189-204.

Quirós Castillo, José Antonio y Tejado Sebastián, José María. Los castillos altomedievales en el noroeste de la Península Ibérica. Documentos de arqueología medieval 4. Bilbao: Universidad del País Vasco, 2012.

Rodríguez Fernández, Justiniano. "Apuntes para la historia de Mayorga». Archivos Leoneses, 1968, vol. 44, p. 318.

Rodríguez Fernández, Justiniano. «El fuero de Laguna de Negrillos». Archivos Leoneses, 1976, vol. 59-60, pp. 291-316.

Rodríguez Fernández, Justiniano. «El fuero de Mayorga de Campos». Archivos Leoneses, 1989, vol. 85-86, pp. 99-128.

Rodríguez Fernández, Justiniano. "Los fueros de Peñafiel (Valladolid) y su notación histórica». Anuario de Estudios Medievales, 1987, vol. 17, pp. 35-42.

Rodríguez Fernández, Justiniano. Reyes de León. Ordoño III. León: Ediciones Leonesas, 1982.

Rodríguez González, Ángel. El tumbo del monasterio de San Martín de Castañeda. León: Centro de Estudios e Investigación San Isidoro, 1973.

Ruiz Asencio, José Manuel y Ruiz Albi, Irene. Colección documental del monasterio de San Pedro de Eslonza (912-1300). Vol. I. León: Centro de Estudios e Investigación San Isidoro, 2007.

SÁnchez Badiola, Juan José. La configuración de un sistema de poblamiento y organización del espacio: el territorio de León (siglos IX-XI). León: Universidad de León, 2002.

Torres SeVILla, Margarita. Linajes nobiliarios de León y Castilla (siglos IX-XIII). Valladolid: Junta de Castilla y León, Consejería de Educación, 1999.

Toubert, Pierre. Castillos, señores y campesinos en la Italia medieval. Barcelona: Crítica, 1990.

VARALdo, Carlo. "Incastellamento e popolamento nel Savonese». En Benente, Fabrizio (a cura di). L'incastellamento in Liguria. X-XII secolo. Bilancio e distini di un tema storigrafico. Bordighera: Istituto Internazionale di Studi Liguri, 2000, pp. 131-161.

VÁzquez Álvarez, Roberto. "Castros, castillo y torres en la organización social del espacio en Castilla: el espacio del Arlanza al Duero (siglos IX a XIII)». En García de Cortázar, José Ángel (coord.). Del Cantábrico al Duero: trece estudios sobre organización social del espacio en los siglos VIII a XIII. Santander: Universidad de Cantabria-Parlamento de Cantabria, 1999, pp. 351-374. 
MARÍA PÉREZ RODRÍGUEZ

CASTROFROILA: LA REPRESENTACIÓN DEL PODER CENTRAL EN LA RIBERA DEL CEA

(SIGLOS X-XII)

VÁzquez Álvarez, Roberto. "Hábitat fortificado y feudalismo en el reino de Castilla entre los siglos viri al XiII». En Quirós Castillo, José Antonio y Tejado Sebastián, José María. Los castillos altomedievales en el noroeste de la Peninsula Ibérica. Documentos de arqueología medieval 4. Bilbao: Universidad del País Vasco, 2012, pp. 291-308.

Vital Fernández, Sonia. Reino e Imperio: poder, negociación y articulación interior en época de Alfonso VII. Tesis doctoral inédita. Universidad de Salamanca, 2012.

Wickham, Chris. «A che sirve l'incastellamento?». En Barceló, Miquel y Toubert, Pierre (dirs.). L'incastellamento. Actas de las reuniones de Girona y de Roma. Roma: École Française de Rome, 1998, pp. 31-42. 
